\title{
ipen
}

Autarquia associada à Universidade de São Paulo

\section{PERCEPÇÃO PÚBLICA DAS INSTALAÇÕES NUCLEARES}

FELIPE DE MOURA KIIPPER

Dissertação apresentada como parte dos requisitos para obtenção do Grau de Mestre em ciências na Área de Tecnologia Nuclear - Reatores

Orientador:

Dr. Antônio Carlos de O. Barroso

SÃO PAULO

2011 


\section{Dedicatória}

Dedico este trabalho àqueles que me inspiraram a busca pelo conhecimento: meus pais Flávio e Marlene Kiipper, meus amigos da República da Gruta, meus amigos do Solo Sagrado e ao prof. Dr. Alexandre Souto Martinez. 
Agradecimentos

Agradeço ao prof. Nelson Barrelo e à coordenadora Marlene, da Escola de Aplicação da USP, e à professora Marlene Kiipper e Diretora Lígia, do Colégio Campos Salles, por permitirem a aplicação do questionário desta pesquisa em seus alunos.

Agradeço à Margarete, do Instituto de Pesquisas Energéticas e Nucleares pelo contato e dedicação para a aplicação do questionário aos alunos visitando o IPEN, à Rita Isabel Ricciardi e ao José Sergio Bleckmann Reis Junior, pela ajuda e opiniões.

Agradeço também ao professor Antonio A. Terremoto, por permitir acompanhá-lo em sua palestra, bem como entrevistar seus alunos.

Por fim, agradeço imensamente aos professores Kengo Imakuma, Antonio Teixeira, e Antonio Carlos de O. Barroso e Diógenes de Souza Bido, pela dedicação e principalmente, pela paciência. 


\title{
PERCEPÇÃO PÚBLICA DAS INSTALAÇÕES NUCLEARES
}

Felipe de Moura Kiipper

\begin{abstract}
Resumo
A chave para o renascimento nuclear é a aceitação pública. Diante das necessidades energéticas que existem em todo o mundo e da escassez dos recursos disponíveis, o trabalho de caracterizar e propor novos modelos para representar a opinião pública é de extrema importância a todos os interessados. Embora o estudo da percepção pública sobre riscos seja recente, diversas abordagens do assunto foram sugeridas e apresentadas, em especial o tema das percepções acerca das instalações nucleares. A definição atual de risco, que transita entre modelos objetivos e subjetivos, reflete as opiniões frequentemente conflitantes do público e de especialistas nesse assunto. Estratégias de comunicação com o público podem ser julgadas a partir dos diversos modelos criados, e seus resultados registrados. O uso de modelos estruturais pode conferir um caráter tanto exploratório quanto confirmatório, sendo assim uma ferramenta adequada para desenvolver estudos sobre o tema da percepção pública em geral. Neste trabalho, um modelo estrutural é reapresentado a partir de dados obtidos num estudo anterior e completado com dados coletados depois do acidente nuclear de Fukushima, no Japão. Os efeitos causados por esse acidente ofereceram uma oportunidade única de estudar a opinião pública por meio dos efeitos de um acidente nuclear e a comunicação de riscos. Paralelamente a esse fato, buscou-se reavaliar o modelo estrutural de acordo com os resultados obtidos, de modo a sustentar um aprimoramento constante das ferramentas de trabalho. Ainda, uma comparação dos dados para grupos de interesse na modelagem de risco é apresentada, especificamente para os grupos de indivíduos do público e especialistas e em seguida, para grupos de alunos antes e depois de uma visita educativa à usina nuclear Almirante Álvaro Alberto. Como resultados, para os modelos estruturais, os dados obtidos foram aplicados aos modelos e analisados por meio de uma análise estrutural da matriz de correlação das variáveis latentes, da magnitude dos coeficientes estruturais e os valores de $\mathrm{R}^{2}$. Resultados indicam que a opinião pública mantém sua rejeição, e que a percepção de benefícios, frente aos riscos percebidos após o acidente, diminuiu. O novo modelo tratou de incluir a variável latente correspondente aos fatores emocionais, cujos resultados aumentaram a explicação da variável dependente, denominada "propensão a aceitar energia nuclear". Já para os grupos analisados, a diferença de opinião entre os grupos segue as características esperadas em cada grupo, e indica alguns pontos de interesse para estratégias de comunicação e entendimento da formação opinião pública e de especialistas. Os efeitos da visita indicam que esta melhora a percepção de benefícios e reduz a percepção de medo e risco, mas que seus resultados podem ser insuficientes para promover uma mudança sólida numa opinião negativa em relação a estas instalações.
\end{abstract}




\title{
PUBLIC PERCEPTION OF NUCLEAR INSTALLATIONS Felipe de Moura Kiipper
}

\begin{abstract}
The key for nuclear renaissance is public acceptance. Facing energetic needs that occur around the world and lack of resources, the work of characterizing and proposing new models to represent public opinion is extremely important to all stakeholders. Even though public opinion's study on risks is relatively recent, may approaches of this subject have been suggested and presented, especially for the topic of perceptions on nuclear installations. Actual definitions on risk exist between objective and subjective models, that reflect opinions of lay public and experts. Strategies on communications with the public may be evaluated from many developed models, and its results may be registered. The use of structural models may present an exploratory character as well as confirmatory theories, as an adequate tool for the development of studies on public perception. In this work, a structural model is presented from data obtained in a previous report, and added to data collected before and after the Fukushima nuclear accident, in Japan. The effects developed from this accident offered a unique opportunity to study public opinion through the effects of a serious nuclear accident and its effects on risk communications. Aside, this work attempted to check the structural model according with obtained results, in order to sustain a constant improvement of the working tools. Yet, a comparison between data according to experts' respondents and lay public ones as well as a comparison among different students before and after a visit to nuclear station is considered. Obtained data for the structural models has been applied for on a structural model and analyzed by structural correlation matrix, latent variable structural coefficients and $\mathrm{R}^{2}$ values. Results indicate that public opinion maintains its rejection on nuclear energy and the perception of benefits, facing perceived risks before the accident, has diminished. A new model that included a latent variable for corresponding emotions returned a stronger dependent variable explanation. As for the considered groups, the different opinions among these groups followed expected characteristics and indicate strategies of communication and of understandment of public and experts opinion elaboration. The effects of the visit indicate a better perception of benefits e deuced perception of risks, but these results may not be sufficient to prompt a solid change on a negative opinion over this subject.
\end{abstract}


SUMÁRIO

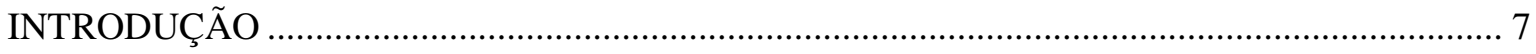

1.1 Histórico da energia nuclear e sua percepção pública................................................................ 7

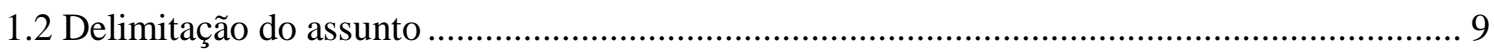

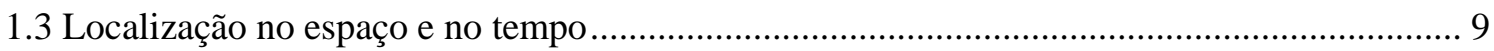

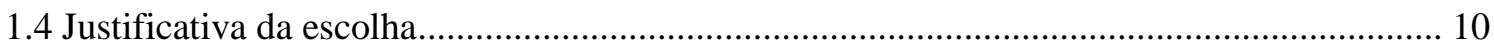

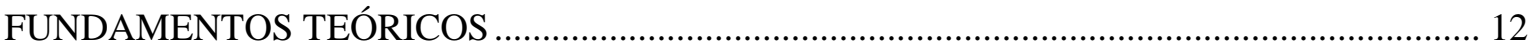

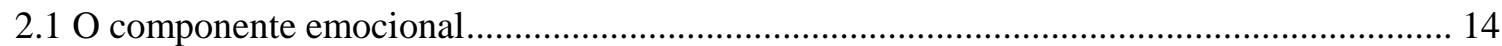

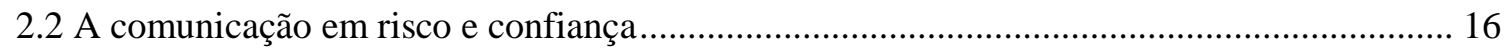

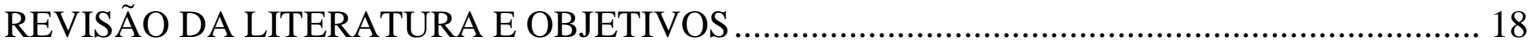

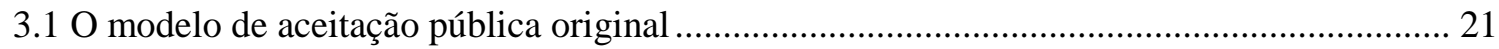

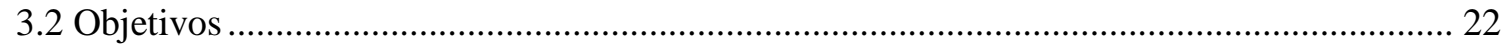

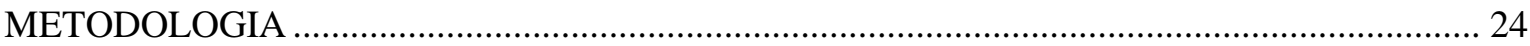

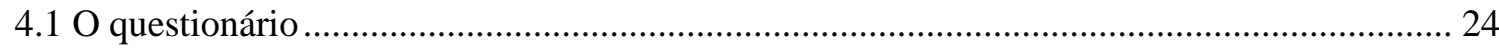

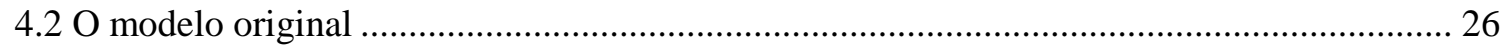

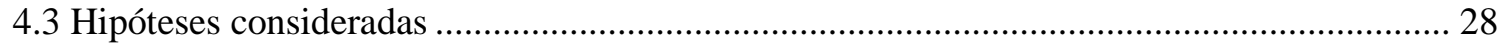

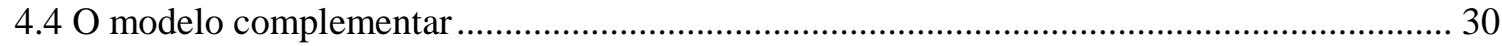

4.5 Os modelos original e complementar, nas perspectivas de risco ............................................ 31

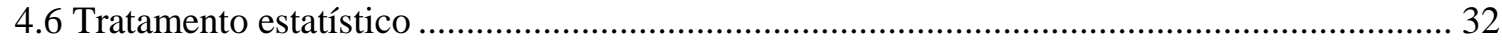

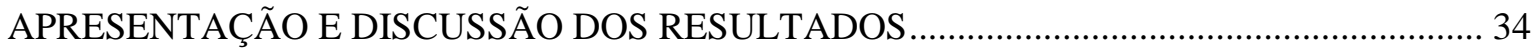

5.1 Comparação dos grupos público e especialistas ...................................................................... 34

5.2 Comparação dos grupos de alunos antes e após visita à usina nuclear.................................... 46

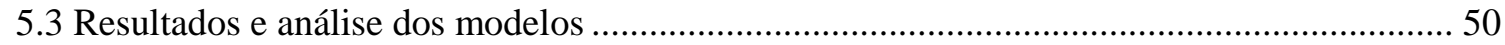

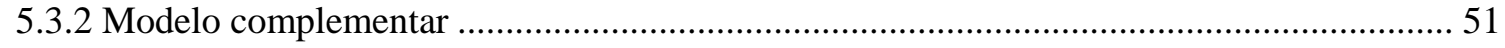

5.4 Discussão dos resultados para os modelos estruturais ............................................................ 52

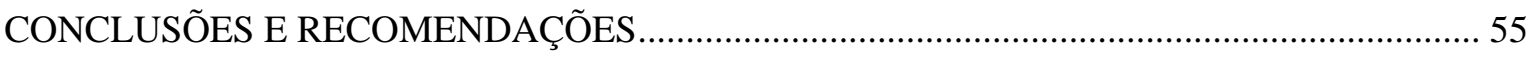

6.1 Percepção pública antes e depois de Fukushima................................................................... 55

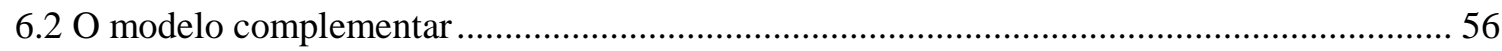

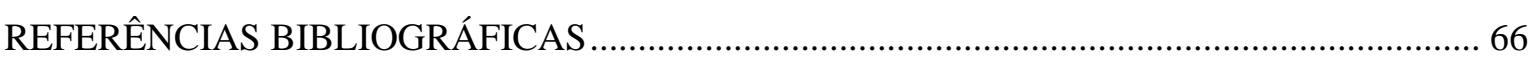




\section{Capítulo 1}

\section{INTRODUÇÃO}

\subsection{Histórico da energia nuclear e sua percepção pública}

Em 2 de dezembro de 1942 ocorria a primeira reação nuclear auto-sustentável em Chicago, nos Estados Unidos. Em 1954, cria-se a primeira usina nuclear civil, Obninsk, na então U.R.S.S. No ano seguinte, a cidade de Arco, em Idaho, seria a primeira a contar com energia elétrica produzida por um reator nuclear experimental. Finalmente, em 1957, a primeira usina nuclear de grande escala entrava em funcionamento em Shippingport, Pensilvânia (U.S. Department of Energy, 1994).

Por meio de seu desenvolvimento, a tecnologia nuclear passou por situações controversas como os acidentes de Three Mile Island, Chernobyl e Fukushima, que a levaram ao centro do debate no conceito moderno de risco. Apesar de a humanidade lidar com riscos desde seu surgimento, as ferramentas para fazê-lo são restritas e sua definição ainda é elusiva, mutável e complexa.

Os primeiros passos para uma interpretação significativa de riscos ocorreram com o surgimento da probabilidade e sua associação com as chances de sucesso. Segundo Bernstein (1996:55), essa revolução iniciou-se na metade do séc. XVI com a publicação de liber de ludo aleae por Girolamo Cardano, para descrever a matemática intrínseca em jogos de azar. As leis da probabilidade porém só ficaram claras em 1645 através do resultado da troca de correspondências entre Blaise Pascal e o matemático Pierre de Fermat. Concretizava-se então uma valiosa ferramenta matemática. Entretanto, embora a análise probabilística tenha adquirido uma vasta aplicabilidade desde seu surgimento, a extensão de seu domínio, quando falamos em riscos, ainda é discutível.

Tal capacidade de aplicação reflete o debate entre a opinião pública e de especialistas, especialmente quando falamos em aceitação tecnológica. 
Historicamente, a aceitação de uma tecnologia sempre esteve ligada ao desempenho econômico (Inhaber, 1982). Uma condição econômica precária leva a uma avaliação das condições de vida da população em termos de sobrevivência ao invés de, por exemplo, bem-estar. Nesse caso, há pouco interesse em discutir impactos ambientais ou de saúde.

Porém, conforme desenvolve-se a economia, surgem novas técnicas e novas informações sobre saúde pública, eventos que frequentemente estão associados a uma crescente influência popular na política e a melhores condições de vida. Esse novo cenário é naturalmente acompanhado de uma mudança de prioridades. São característicos desse período o surgimento de agências de proteção ambiental, a bandeira do "ambientalismo" e uma consequente expansão da cobertura do assunto pela mídia. Notoriamente, apesar desse processo ser o resultado de uma busca por sociedades mais seguras, o público curiosamente se tornou mais preocupado com riscos. De acordo com Slovik (1999:689), "esses indivíduos vêem a si mesmos como expostos a riscos mais graves que os enfrentados pelas pessoas no passado, e acreditam que a situação está ficando pior, ao invés de melhor."

Concomitantemente, surgiam instituições cuja tarefa se concentrava em regular instalações perigosas e riscos potencialmente grandes. Especificamente, cabia e cabe a essas instituições emitir permissões e regimes de licenciamento. Ocorre que, diante de recursos limitados e frente à complexidade do assunto de risco e das instalações envolvidas, decidiu-se por implementar um esforço para otimizar a maneira com a qual os riscos são trabalhados. Este trabalho pode ser entendido como parte deste esforço.

No desenvolvimento dessa otimização, para os casos em que as partes envolvidas não estão familiarizadas com o assunto e as decisões a serem tomadas são particularmente complexas, criou-se métodos de avaliação de opinião e da percepção de riscos, tanto para indivíduos como para grupos sociais. Essa disciplina emergiu na década de 60 por meio do estudo de dados envolvendo a segurança ocupacional e saúde (Williamson \& Weyman, 2005).

O problema da opinião pública ganhou espaço nas ciências socias e comportamentais a partir da década de 80 , com grande foco na percepção de risco com estudos como os de Paul Slovic (1987) e em 2000, no papel das decisões políticas, com Lennart Sjöberg $(2003,2000)$. 


\subsection{Delimitação do assunto}

A aplicação de conceitos relacionados à percepção pública de instalações nucleares é o objetivo geral deste trabalho. A delimitação deste trabalho segue limites práticos e considerações teóricas.

A complexidade da percepção pública, mesmo quando focada em instalações nucleares, é considerável. Torna-se dispendioso tratar do assunto como um todo, de tal forma que reduções são necessárias. Assim, este trabalho considerou o problema da comunicação de riscos. A escolha baseia-se no fato da percepção pública de instalações nucleares ser sustentada principalmente pelo processo de comunicação e transmissão de fatos e pensamentos, já que experiências diretas com usinas nucleares são raras em todo o mundo.

Em todo caso, é interessante colocar alguns resultados obtidos a partir de estudos com populações que residem próximas a instalações nucleares. Essas populações podem muito bem ser caracterizadas como um segmento cuja percepção é formada principalmente pelas experiências diretas com o elemento de risco, e podem ser utilizadas para fins de comparação com grupos que dependem dos meios de comunicação.

Por exemplo, resultados apresentados por Ann Stouffer Bisconti (2011a) numa pesquisa realizada com a população americana após o desastre de Fukushima, indicou que dos indivíduos que residem próximos às instalações nucleares, uma fatia de $80 \%$ expressa uma opinião favorável à energia nuclear. A mesma pesquisa, quando direcionada à população americana em geral apontou uma parcela equivalente de 62\% (Bisconti Research, 2011b).

\subsection{Localização no espaço e no tempo}

Embora este trabalho limite-se a uma amostra de conveniência, a percepção pública deve grande parte de sua complexidade à densa rede de comunicação entre as pessoas de diversas origens. A intensidade desta relação interpessoal é evidente quando pensamos no alcance desenvolvido pelas notícias de um acidente qualquer de interesse, ao redor do mundo.

Define-se a localização no espaço deste trabalho pela área da cidade de São Paulo onde aplicaram-se os questionários. Porém, embora as inferências estatísticas apresentadas aqui sejam restritas a uma amostra de conveniência, seu entendimento deve certamente incluir efeitos causados por fatores externos ao espaço apresentado. A análise 
neste trabalho busca entender e desenvolver modelos, e não descrever a opinião de uma população a partir de uma amostra. Os dados devem portanto enquadrar, da maneira mais adequada possível, os efeitos da percepção pública sobre a amostra, a partir de qualquer parte do mundo, como notícias e eventos internacionais.

A coleta de dados ocorreu 6 meses após a sequência trágica de eventos na usina nuclear de Fukushima, em 11 de março de 2011. Certamente, os efeitos deste acidentes estão moldando os dados obtidos. Dado que eventos desta magnitude podem redirecionar consideravelmente a opinião pública, podemos tratar os dados obtidos nesta pesquisa como pertencente a uma época "pós-Fukushima", para efeitos de localização no tempo e comparação com outros trabalhos. Os dados coletados em um outro trabalho anterior (Barroso, 2010), num momento "pré-Fukushima” também foram utilizados.

É necessário reconhecer que há limites nessa comparação. Os dados coletados apresentariam uma comparação ideal entre os momentos pré e pós-Fukushima caso fossem obtidos imediatamente antes e depois do acidente, e de preferência com o mesmo grupo de pessoas. Porém, considerando a incapacidade de prever um acidente, o intervalo de tempo captado é certamente satisfatório, bem como a amostra populacional, para objetivos tais como definir o rumo de possíveis novos estudos e analisar modelos.

\subsection{Justificativa da escolha}

O futuro das usinas nucleares depende em grande parte da opinião pública (Naidoo, 2006). Cabe a qualquer sociedade que participe das tecnologias nucleares conhecer a opinião pública sobre essa tecnologia, de modo a otimizar a sua aplicação e reconhecer a importância da participação do público em sociedades democráticas.

Havendo discordância entre especialistas e público, a justificativa para o estudo da opinião pública não reside numa tentativa de alcançar uma situação de grande convergência de opiniões, ao contrário da noção recorrente. Conforme exemplificado por Sjöberg, (2006), no leste europeu a grande confiança em administradores, políticos e industrialistas resultou em negligência por parte destes quanto a assuntos pertinentes ao meio ambiente. A pressão popular é o mecanismo que impulsiona esse segmento de modo a cumprir com suas obrigações. Sjöberg conclui ainda que sociedades democráticas nunca vão convergir para um cenário de opiniões iguais, já que a tarefa intrínseca da mídia é sempre reportar riscos e perigos. 
A importância do estudo da percepção pública de riscos deve justificar-se numa busca por sociedades diversificadas. De acordo com Sjöberg (2006:695),

"Tal sociedade, com suas eventuais dinâmicas dolorosas, parecem ser muito mais preferíveis do que sociedades onde todos concordam com um risco. Diversidade é alegria."

Portanto, conhecer e estudar a opinião pública está no centro do entendimento e é um desafio para as sociedades democráticas. Instalações nucleares carregam uma controvérsia valiosa para estudo, além de uma necessidade inquestionável se considerarmos a necessidade de energia elétrica e seu desafio atual para obtê-la de modo responsável.

Atualmente, vivemos num mundo de crescente demanda por energia, onde a principal fonte de eletricidade são combustíveis fósseis, cujos efeitos secundários vão contra a uma crescente preocupação com a emissão de gases estufa. Não sendo esta uma características das instalações nucleares, sua importância como fonte de energia presente e futura é evidente.

O entendimento da percepção pública, tanto qualitativo quanto quantitativo interessa diretamente a políticos, agências regulatórias, companhias e organizações nãogovernamentais envolvidas no assunto. 


\section{Capítulo 2}

\section{FUNDAMENTOS TEÓRICOS}

\[ \text { É fundamental em qualquer estudo de risco entender seu conceito e } \]
característica dual, especialmente quanto trata-se de sua definição. Na condição da
percepção de risco em instalações nucleares, essa dualidade é encenada por especialistas e
público.

Embora seja tentador definir riscos como uma probabilidade de perda ou dano, esta definição é insuficiente. O risco é um conceito criado pelas pessoas para lidar com o mundo que as cerca, e portanto é, em essência, subjetivo. Isso significa que, embora seja possível expressar um risco por meio de uma probabilidade de uma certa consequência, o ato de escolher qual probabilidade melhor caracteriza a consequência em questão varia de indivíduo para indivíduo. Slovic ilustra essa dualidade (Slovic, 1999) com um exemplo apresentado por Wilson e Crouch (1982): Entre as décadas de 50 e 70, constatou-se que algumas minas de carvão ficaram menos arriscadas em termos de mortes por toneladas de carvão extraídas, mas ficaram um pouco mais arriscadas em termos de mortes por operário contratado. Podemos dizer que, para governantes que consideram a importância de obter uma certa quantidade de carvão, o risco diminuiu, enquanto que para um sindicato de trabalhadores, aumentou.

Embora o risco seja sem dúvida subjetivo, não seria possível tomar decisões e conclusões se por vezes não o tratássemos como um conceito objetivo.

A dualidade pode também ser ilustrada na definição de risco como um constructo desenvolvido pelas pessoas (subjetivo), ou uma característica ou propriedade intrínseca do objeto de estudo, que independe do observador (objetivo).

Assim, para o estudo do risco em qualquer que seja seu contexto, é necessário desenvolver modelos cada qual com sua interpretação do conceito de risco devidamente 
explicitada a partir da dualidade apresentada. Logicamente, essa interpretação deve se adequar ao contexto e objetivos propostos no momento do seu desenvolvimento.

Atualmente, a tarefa de caracterizar um modelo tornou-se complexa, e a comunicação entre pesquisadores exigiu o estabelecimento de padrões e conjuntos prédefinidos de modelos de risco. A contextualização de cada modelo passou a exigir uma nova forma de representação, na qual as perspectivas podem ser caracterizadas.

Desta maneira, os modelos desenvolvidos para descrever riscos são ilustrados num eixo que estende-se de aproximações realistas a construtivistas (Williamson \& Weyman, 2005), relacionados com o conceito de risco como objetivo e subjetivo, respectivamente. Cada modelo, de acordo com sua afinidade com cada perspectiva, posiciona-se adequadamente ao longo deste eixo.

Acrescenta-se a este eixo a representação de modelos que tratam dos indivíduos até modelos que tratam de grupos sociais. Essa distinção segue a classificação de pesquisas nas ciências sociais em duas escolas que são, de acordo com Pidgeon (1998), a aproximação psicométrica empírica e as teorias culturais de risco. Respectivamente, essas abordagens correspondem a modelos interessados nos processos que tomam parte nos indivíduos e nos grupos sociais.

De mesma maneira, pode-se definir um eixo entre essas representações, perpendicular ao primeiro. Assim, a associação dos dois eixos descritos permite a construção de um espaço bidimensional no qual os modelos de risco podem ser identificados. Cada modelo de representação de risco, quando representado no plano citado, evidencia os limites intrínsecos da dualidade do risco no próprio modelo.

Alguns dos principais modelos e conceitos de percepção pública que podem ser expressos nesse diagrama, representado na fig. 1 a seguir, são: aproximação psicométrica, modelos mentais, cultura de segurança, aproximação cultural, amplificação do risco e modelos racionais. Os modelos de interesse nesse trabalho serão brevemente apresentados na seção "revisão da literatura". 


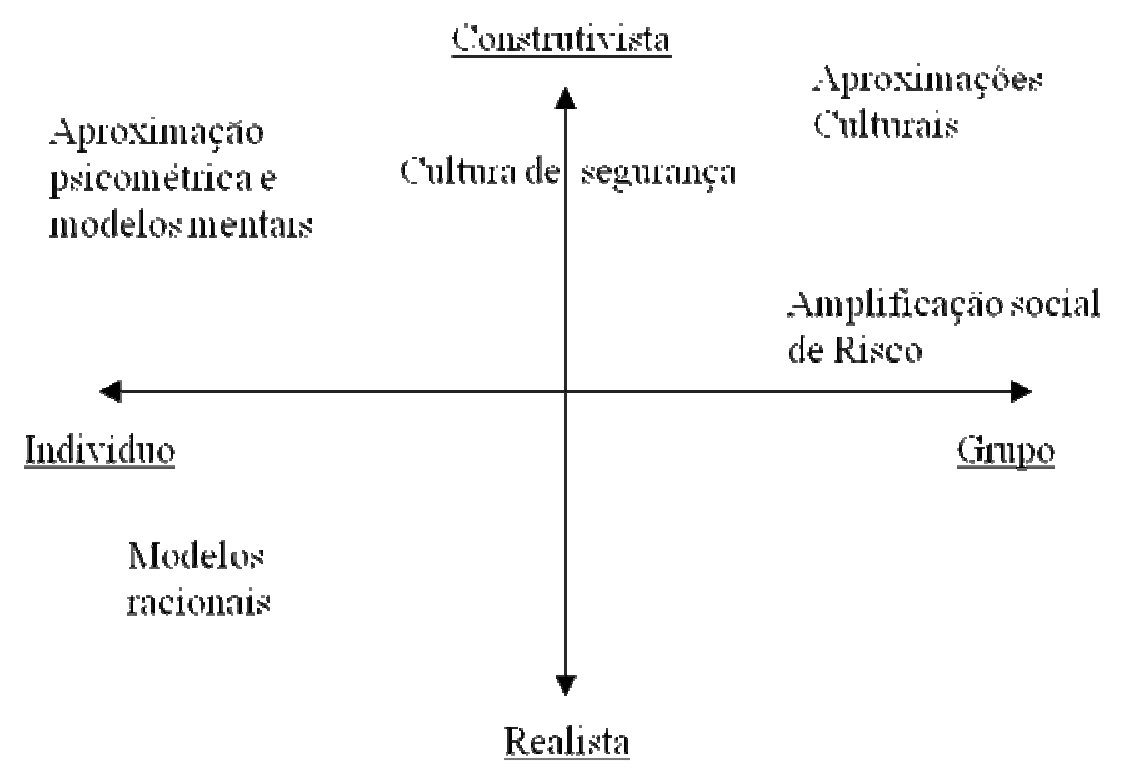

Figura 1 - Perspectivas em risco, Williamson \& Kelley (2005)

\subsection{O componente emocional}

Muitos modelos participam de uma contextualização construtivista do risco. Esse fato reforça o reconhecimento da subjetividade como raiz na formulação de riscos. Podemos argumentar também que seria complicado definir um modelo que associasse a perspectiva realista a grupos sociais, daí a ausência de modelos no quarto quadrante do plano cartesiano. Essa dificuldade emerge da complexidade das relações sociais e sua volubilidade. Uma construção racional e mais realista (objetiva) é melhor entendida ao estudarmos o indivíduo.

Apesar da provável dificuldade, é necessário integrar os modelos, ou eventualmente tentar entender de que modo as interações entre as diferentes perspectivas ocorrem, particularmente observando o eixo dos conceitos individualista e de grupo social.

O papel desempenhado pelas emoções na construção de risco só passou a ser melhor entendido recentemente (Slovic et al., 2004). Considerando que as emoções atuam como indicadores para a tomada de decisões diante de um risco, é possível entendê-las como uma heurística intrínseca, secular e natural do ser humano. Sua importância têm se tornado cada vez mais evidente.

A principal vantagem de uma "decisão emocional" sobre uma estratégia racional é seu curto tempo de resposta, especialmente quando decisões têm de ser tomadas a cada instante. O uso da razão é consideravelmente mais dispendioso, longo e requer um nível maior de processamento consciente (Slovic et al., 2004). 
O valor da tomada de decisões a partir das emoções é bem colocado pelo neurologisa António Rosa Damásio (1994), que argumenta que o conteúdo emocional é criado a partir de experiências positivas e negativas. Especificamente, há no cérebro um processo de associação de imagens carregadas de significados emocionais com uma dada experiência, quando vivenciada. Essa conexão permanece por certo tempo, de modo que diante da necessidade de tomar uma decisão, o cérebro evoca as imagens relacionadas, levando também a emoção a ela associada.

Logo, a emoção não é tão caótica como se poderia supor, e seu uso deve constituir uma resposta a um risco, no mínimo, considerável.

A questão que surge aqui é de que modo essas observações, que tratam da decisão de risco a partir das emoções, podem ser extendidas do indivíduo para um grupo social, isto é, se as emoções quando processadas por um grupo social ainda podem sustentar sua coerência.

Particularmente a percepção de riscos, apesar de desenvolvida no indivíduo, expressa-se melhor num grupo social. Os limites dessa questão, bem como de qualquer modelo que trata do indivíduo, são relevantes para a significância de uma conclusão.

Ambas as estratégias de decisão de risco, seja por meio da razão, seja por meio da emoção, trabalham em paralelo. Há vestígios emocionais em toda decisão lógica e viceversa. Cada estratégia terá suas vantagens, viéses e limitações.

O entendimento da influência das emoções na avaliação do risco e sua consequente decisão devem ser colocados diante do debate que se desenrola entre especialistas e público.

Para a questão da construção e uso de instalações nucleares, especialistas normalmente se apóiam em probabilidades e dados para sustentar uma posição frequentemente favorável ao uso desse tipo de energia. O público, por outro lado impulsionado por emoções, notoriamente o medo, associações com acidentes e até mesmo associações com artefatos como a bomba atômica, costuma se opor a instalações nucleares.

Embora autoridades tenham a tendência a favorecer a opinião de especialistas, deve-se reconhecer que mesmo experts estão sujeitos a influências emocionais (Slovic, 1999). Observando ainda que o próprio público é o elemento central exposto ao risco, podemos dizer que cabe aos interessados em risco estabelecer uma análise crítica de suas conclusões, independente de onde se originam. 


\subsection{A comunicação em risco e confiança}

Um elemento chave na compreensão de riscos para este estudo é a comunicação. Conforme afirmado anteriormente, esse conceito apresenta um papel central na percepção de riscos para instalações nucleares, pois o público majoritariamente depende dos meios de comunicação para obter informações sobre esse tema.

Os efeitos da comunicação de risco possuem diferentes abordagens técnicas, como o conceito de enquadramento (framing of risk) (Weyman \& Kelly, $1999 \mathrm{e}$ Williamson \& Weyman, 2005), o debate sobre a eficácia da comunicação de dados e representações numéricas (Williamson \& Weyman, 2005) e o conceito de amplificação social de riscos (Breakwell et al., 2001 e Renn 2003). Neste trabalho, os meios de comunicação são separados entre interações mediadas e interações pessoais (Kiipper et. al., 2011), dependendo da presença ou não de um veículo de comunicação.

Há uma intensa pesquisa sobre a comunicação de riscos, em parte devido aos esforços implementados por diversas nações nesse sentido. Há, por exemplo, a crença de que a comparação entre conceitos de riscos extraordinários (tais como os de uma usina nuclear) com riscos do cotidiano pode ser um método interessante de provocar a assimilação de probabilidades relativas ao risco, por parte do público. Sabe-se que o público difere dos especialistas notoriamente na interpretação de dados e probabilidades, por vezes devido a viéses reconhecidos. Por exemplo, dados referentes a fatalidades num contexto de risco são interpretados e aplicados em argumentos diferentes pelo público e por especialistas (Kemp, 2002). Porém, as diferenças entre público e especialistas não podem ser caracterizadas unicamente pela falta de perícia (Walker, 1998).

Para os meios de comunicação em massa, ressalta-se que a comunicação nestes por vezes evita a "ciência real", o jornalismo investigativo e têm preferência por temas controversos e incerteza, já que estes agarram mais a audiência (Williamson \& Kelley, 2005). Esses impactos podem ser bem discutidos como uma forma de amplificação de risco.

De acordo com Sauer \& O. Neto (1999), o processo de elaboração de uma matéria pela mídia é comprometido pela falta de preparo técnico-científico para lidar com as informações, agenda limitada e dificuldade em julgar a competência das fontes. Acresenta-se a isso a pressão de grupos para apresentar matérias em determinado formato, o que por vezes compromete seriamente sua imparcialidade. 
Ribeiro Jr. (2007:12) aponta ainda algumas causas do fracasso da comunicação de risco:

"Não há sintonia na linguagem de especialistas com o público e, em parte, porque nem mesmo entre os especialistas há consenso sobre os riscos. A percepção do público pode ser exagerada ou reduzida em relação ao que lhes é comunicado. Um exemplo de subestimação é o caso da exposição ao sol em que na prática aumenta o risco de câncer de pele e, mesmo assim, a população ignora as recomendações dos especialistas"

Este mesmo autor cita os tradicionais programas de comunicação de risco no Brasil, onde o tema de segurança em energia nuclear frequentemente salienta o uso desse tipo de energia para fins pacíficos. Ribeiro Jr. (2007) argumenta que se a constituição brasileira já exclui obrigatoriamente o uso dessa tipo de energia para fins bélicos, logo reafirmar o uso para fins pacíficos de nada serve além de lembrar da ameaça nuclear no mundo.

Portanto, a comunicação de riscos é elemento fundamental para tratar da percepção pública, e ao mesmo tempo é um assunto delicado e que requer muito conhecimento sobre as técnicas de comunicação.

Outros estudos apontam não só a comunicação como a confiança como outro conceito importante para desenvolver e mudar a percepção de riscos (Pidgeon et al., 1992). Especialmente para as instituições responsáveis pelo risco em questão e para as agências e jornalistas que desenvolvem a comunicação de riscos, a questão da confiança é um amplificador importante. Sua característica assimétrica é uma de seus pontos mais interessantes, onde a confiança pode ser prontamente destruída, enquanto leva muito tempo para ser estabelecida. 


\section{Capítulo 3}

\section{REVISÃO DA LITERATURA E OBJETIVOS}

Estudos da percepção de risco e métodos de aplicação de questionários são áreas cujo desenvolvimento é recente. Embora isso seja em parte devido ao uso de linhas de pensamento relativamente novas como a psicologia, é também devido à falta de interesse e necessidade de agências e organizações até então. Tais agências surgiram a partir da atual pressão pública, resultante de sociedades que estão economicamente desenvolvidas.

Desse modo, observa-se que a grande maioria dos conceitos utilizados nesta área foram apresentados pelos pesquisadores na década de 90 (S. Hunt, L.J. Frewer, N. Pidgeon, P. Slovic, L. Sjöberg, A.K. Weyman e C.J. Kelly) e 2000 (A.F. Wålberg, G.M. Breakwell, F. Fischer, G. Gaskell, R.V. Kemp, J.X. Kasperson, J. Petts, M. Power).

Dentre os modelos apresentados na introdução, um número considerável de autores têm se concentrado nas características racionais que constituem uma decisão. (Starr, 1969; Weyman \& Kelly 1999 e Williamson \& Weyman, 2005). Basicamente, esses modelos tratam a decisão de risco como o resultado de uma escolha racional e individual, onde o processo pode se resumir a uma comparação entre riscos e benefícios.

Porém o conceito de risco, quando considerado particularmente racional, acaba por considerar como um viés os diferentes valores e significados específicos dos riscos e benefícios. A subjetividade intrínseca presente nesses conceitos, e especificamente o modo como as informações são individualmente processadas, num procedimento conhecido como "interpretação pessoal do mundo" são os principais desafios neste caso (Williamson \& Weyman, 2005). É importante reconhecer que a complexidade do mundo real, diante da capacidade de processamento limitada do indivíduo, exige uma aplicação de atalhos e 
simplificações mentais. Esses elementos são característicos e indissociáveis do pensamento humano.

A partir do modelo de decisão de custo e benefício, é possível estender outros modelos fundamentados nas mesmas condições. Por exemplo, tomamos modelos que procuram entender a motivação de cada indivíduo a se proteger ou não de um risco a partir do seu entendimento do risco e percepção de vulnerabilidade. Os fundamentos são semelhantes, pois de mesma maneira, supõe-se uma interpretação racional entre o entendimento do risco e a percepção da vulnerabilidade.

Embora estes modelos se adaptem bem aos limites da interpretação racional, sua confiabilidade é minada, entre outros aspectos, pela falta de consideração nas inúmeras situações possíveis no entendimento de um risco qualquer. Novamente, o caráter subjetivo do risco acaba por aceitar visões diferentes sobre um mesmo elemento, tornando a tarefa de constituir valores muito complexa.

Ainda no campo dos modelos interessados no indivíduo temos o modelo da aproximação psicométrica, definido pelo o uso de técnicas estatísticas multivariadas para entender a atitude expressada por uma amostra populacional (Williamson \& Weyman, 2005). Assume-se que a percepção é influenciada pelas características do elemento que apresenta o risco, embora a determinação do perigo seja em último caso um processo subjetivo.

Weyman e Kelly (1999) apontam como crítica a esse modelo a forma como sua aplicação pode influenciar resultados. Modelos psicométricos partem de questionários cujas próprias questões, dependendo do modo como são formuladas, podem influenciar os respondentes. O tamanho da amostra pode também apresentar uma barreira para dados concisos. A indistinção entre conceitos realistas e subjetivos pode ainda causar alguma confusão (Wåhlberg, 2001).

Resultados nesse tipo de análise apontam fatores como medo e familiaridade (ou incerteza) como potenciais indicadores da percepção pública (Pidgeon, 1998), e em alguns casos ressaltou-se a igualdade, uma distribuição justa do risco e a responsabilidade associada, como outros fatores relevantes para a elaboração de uma conclusão (Walker et al., 1998).

Ainda para os modelos que se concentram nas qualidades do indivíduo, apresentam-se os modelos mentais. Essa aproximação identifica diferenças entre as percepções de público e especialistas, através de suas interpretações de mundo (Williamson \& A. Weyman, 2005). Estes modelos têm avançado no entendimento da 
diferença sobre a caracterização de risco entre os grupos de indivíduos do público e especialistas, obtendo conclusões diferenciadas se comparadas aos demais modelos. Por exemplo, de acordo com Weyman e Kelly (1999), estudos com estes modelos obtiveram as seguintes conclusões:

- Dificuldade da população em distinguir entre exposição fracionada e exposição única;

- Viés otimista, onde as pessoas julgam seu comportamento de risco como menos arriscado do que o mesmo comportamento, quanto praticado por outros;

- Persistência em busca por explicações do tipo causa e efeito, para situações que às vezes podem ser demasiado complexas. A insistência pode levar a uma associação enviesada ou incorreta de dois fatores próximos.

Um método conhecido, caracterizado como modelo mental, é o Laddering Methodology, que busca dividir uma linha de raciocínio pressuposta em etapas de modo a identificar, para diferentes indivíduos, semelhanças e divergências em seus pensamentos. Nesse modelo, as questões são formuladas frequentemente através de entrevistas semiestruturadas. A crítica para esse modelo, bem como para outros tipos de modelos mentais, é a noção exagerada de consenso dada a especialistas no risco em questão (Weyman \& Kelly, 1999).

Os demais modelos apresentados na Fig. 1 estão fundamentados na tendência a identificar a percepção de riscos a partir de seu contexto cultural, social e político. Esse modelos constituem uma análise dos processos sociais, especificamente na capacidade que estes têm de formar a opinião individual. De acordo com Frewer (2001), o risco não pode ter seu valor determinado ou ser avaliado independentemente do sistema social no qual se encontra.

De uma maneira geral, podemos dizer que a teoria cultural classifica alguns tipos de interações pessoais através dos quais se formam e transformam as opiniões públicas. Por exemplo, temos interações classificadas como igualitária, hierárquica, individualista, fatalista e eremita. Entre os modelos de cultura de segurança, aproximações culturais e amplificação social de risco, o último é de interesse especial neste trabalho.

Pelo conceito de amplificação social de risco verifica-se como as características de um perigo podem interagir com processos sociais, culturais e psicológicos, que enfraquecem ou reforçam uma percepção do risco. Pesquisas nesta área 
estimulam o interesse nos processos sociais que moldam a percepção de risco, especialmente a mídia e demais fontes de informações.

\subsection{O modelo de aceitação pública original}

O principal modelo de interesse nesse trabalho é o modelo estrutural apresentado por Barroso (2010) para a exploração de fatores determinantes na aceitação pública para a energia nuclear e confirmação de hipóteses.

Nesse modelo, a elaboração da opinião pública é detalhada desde a apresentação dos fatos (notícias) ao indivíduo até o desenvolvimento de uma propensão para aceitação de instalações nucleares. Esta última variável latente é o principal objeto de estudo, e portanto a variável dependente.

Particularmente, o processo pode ser entendido em duas partes, a primeira corresponde à apresentação das informações até sua internalização pelo indivíduo, e a segunda parte corresponde ao processo de decisão formado a partir dessas informações já internalizadas.

O modelo é constituído pelas variáveis latentes, representadas na fig. 2 por balões, e correlacionadas por hipóteses a serem testadas, representadas pelas setas entre as variáveis latentes. Todas as correlações, bem como as variáveis latentes serão descritas no capítulo seguinte. O sinal “(+)”, presente nas hipóteses descritas significa que essa correlação em questão foi postulada como uma correlação positiva, ou seja, espera-se que o aumento em determinada variável latente represente um respectivo aumento naquela variável correlacionada.

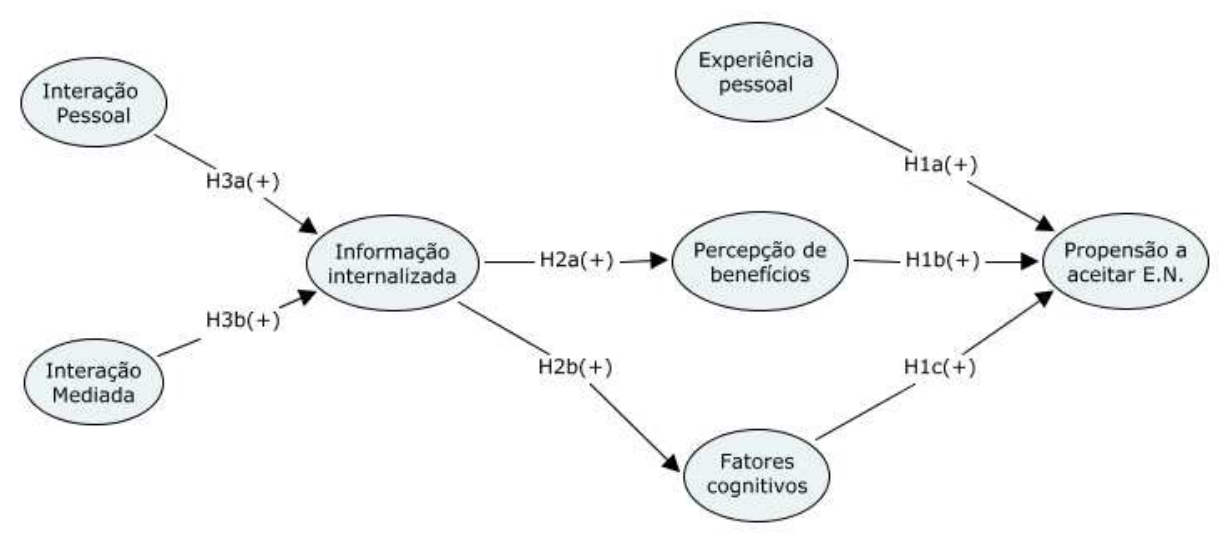

FIG. 2 - O modelo original para propensão da aceitação de E.N. (Barroso, 2010) 


\subsection{Objetivos}

Este estudo tem como objetivo central considerar modelos de percepção de risco presentes na literatura especializada e contribuir para o entendimento da opinião pública em relação às instalações nucleares (especificamente para as instalações de geração de energia nuclear), através de um modelo estrutural desenvolvido para trabalhar a questão da comunicação.

Embora a amostra tomada seja uma amostra de conveniência, essa pesquisa caracteriza a opinião pública das instalações nucleares de um grupo de interesse para diversos interessados, como ONGs, especialistas e políticos, entre outros.

Os indivíduos entrevistados podem caracterizar grupos de interesse para o entendimento da percepção pública. Num primeiro momento, todos os indivíduos entrevistados puderam ser divididos entre especialistas e público, de acordo com critérios que serão apresentados a diante. Já numa outra etapa, uma parcela dos entrevistados, correspondente a alunos do ensino médio, pode ser dividida entre aqueles que já visitaram

a Central Nuclear Almirante Álvaro Alberto (Usina Nuclear de Angra dos Reis) através do programa de visitação da usina, e aqueles que ainda não participaram efetivamente desta visita.

Para ambos os casos apresentados acima, é possível comparar cada par de grupos apresentados, buscando identificar diferenças e comparando-as no primeiro caso (especialistas e público), e no segundo, registrar os efeitos da visita, sobre aspectos da percepção e aceitação de instalações nucleares para geração de energia elétrica.

Numa outra etapa do trabalho, temos alguns objetivos que precisaram ser redesenhados ao longo do trabalho. Inicialmente, esses objetivos consistiam em elaborar um novo modelo a partir do modelo criado por Barroso (2010). Esse novo modelo, mais completo, seria proposto para explicar melhor a opinião pública, observando as mudanças que tomaram parte num período relativo de coleta de dados, sem considerar a presença de eventos de impacto significativo. Porém, eventos presentes do decorrer do trabalho trouxeram novas possibilidades. Os objetivos foram reformulados conforme a seguir:

\subsubsection{A percepção pública e o acidente em Fukushima}

Conforme mencionado, durante o desenvolvimento deste trabalho, a tragédia na usina nuclear de Fukushima, Japão, tomou parte. Observou-se que a presença de dados sobre a opinião pública antes do acidente permitiria que o novo questionário captasse a mudança na percepção pública sobre as instalações nucleares devido a este acidente em si, 
somado a outros demais fatores presentes no breve espaço de tempo entre as coletas de dados.

Há, portanto, um enfoque adicional na análise do trabalho, onde assume-se a presença do acidente como principal causa da alteração da opinião pública, reduzindo a necessidade de introduzir outros possíveis fatores para a evolução da opinião pública. Esta suposição é razoável principalmente quando se considera que o intervalo de tempo entre as duas amostras foi inferior a um ano.

Fica como objetivo, entre outros, reproduzir a metodologia aplicada por Barroso et. al. para dados coletados antes e depois do acidente em questão e comparar resultados. Como há limites para que essa comparação possa ser definida como um resultado moldado apenas pelo acidente em si, para uma leitura metódica esse resultado deve ser interpretado como a soma dos fatores desenvolvidos entre o intervalo de tempo de coleta dos dados, nos quais o acidente está certamente incluído e toma boa parte da influência. Quantificar a proporção da influência do acidente nos resultados coletados está fora do escopo desse trabalho.

\subsubsection{Aprimoramento do modelo original: o modelo complementar}

Como retomamos um modelo já utilizado, a pesquisa deve também reconsiderar a validade desse modelo, julgá-lo e propor melhoras. Essa reformulação do modelo parte de uma proposta de dar maior foco ao componente emocional no processo decisório, e também será testada. Em contraste ao modelo original, este modelo será denominado "modelo complementar".

Dada a complexidade da opinião pública e a necessidade de seu entendimento, a busca por canais de comunicação, de acordo com sua eficiência, será explorada. Entre aqueles fatores que constituem a opinião pública, espera-se indicar os que têm maior influência na aceitação pública. 


\section{Capítulo 4}

\section{METODOLOGIA}

Sendo o modelo estrutural desenvolvido por Barroso et al. (2010), o principal instrumento usado para a caracterização da opinião pública neste trabalho, o tratamento inicial resume-se a estudar este modelo utilizando os resultados obtidos antes do acidente em Fukushima. Os dados utilizados para este caso já haviam sido coletados em paralelo a este projeto, numa pesquisa na cidade de São Paulo, e sua análise e interpretação dos resultados foram apresentados na $6^{\text {th }}$ Dubrovnik Conference on Sustainable Development of Energy, Water and Environment Systems (Kiipper et. al., 2011). Esses serão portanto os resultados comparados com dados obtidos na nova aplicação do questionário.

\subsection{O questionário}

O questionário desenvolvido para este trabalho deve conter as mesmas questões utilizadas no questionário antigo para que a comparação de resultados antes e depois do acidente de Fukushima seja efetiva. Ainda, no mesmo questionário foram acrescentadas algumas questões onde julgou-se pertinente a caracterização do componente emocional (questões 12 a 22), para compor o modelo complementar, conforme os objetivos apresentados. Este questionário conta então com um total de 30 itens, sendo portanto 19 questões "antigas" e 11 as questões novas. Para permitir uma análise quantitativa dos dados e evitar o cansaço dos participantes, optou-se por manter sempre questões de múltipla escolha. Os questionários foram aplicados mediante assinatura de um termo de esclareciemento livre e esclarecido (APÊNDICE A) e uma breve instrução sobre como responder as questões. O tempo de resposta variou entre 10 e 20 minutos. 
Um modelo do questionário pode ser encontrado no APÊNDICE B. As questões foram aplicadas a 512 participantes, divididos em sete grupos, de acordo com os contextos e situações onde os questionários foram aplicados:

TABELA 1 - Número de participantes por grupo

\begin{tabular}{clc}
\hline & \multicolumn{1}{c}{ Grupo } & Participantes* \\
\hline A & Alunos de física da USP e profissionais do IPEN & $18(18)$ \\
B & Alunos do Ensino Médio do Colégio “Campos Salles” & $81(79)$ \\
C & Visitantes do reator do IPEN & $49(47)$ \\
D & Alunos de engenharia da UNIFESP - Diadema & $9(8)$ \\
E & $\begin{array}{l}\text { Alunos do ensino médio da escola de aplicação da USP, que } \\
\text { ainda não visitaram a usina nuclear de Angra dos Reis }\end{array}$ & $112(103)$ \\
F & $\begin{array}{l}\text { Alunos do ensino médio da escola de aplicação da USP, que } \\
\text { já visitaram a usina nuclear de Angra dos Reis }\end{array}$ & $55(55)$ \\
G & Alunos do ensino médio de escola pública & $188(153)$ \\
\hline * número entre parênteses representa o número de questionários válidos
\end{tabular}

* O número entre parênteses representa o número de questionários válidos

Para o tratamento dos dados, primeiramente identificou-se aqueles questionários cujo número de respostas em branco era maior que 10\%. Esses compreenderam 49 questionários e foram excluídos da pesquisa.

Testou-se também a ocorrência de respostas idênticas compulsivas, ou seja, questionários onde os respondentes assinalavam insistentemente a mesma alternativa para diferentes questões. Para esse critério, não houve casos que justificassem a exclusão.

Os grupos foram rearranjados da seguinte forma: primeiramente foram divididos entre aqueles que possuem e os que não possuem conhecimentos específicos e/ou interesse em tecnologia nuclear. Separam-se assim os grupos B, E, F e G dos demais como aqueles que não possuem o conhecimento/interesse específico.

Esses quatro grupos possuem características suficientemente semelhantes ao grupo de indivíduos selecionados para o questionário pré-Fukushima, onde foram selecionados estudantes do ensino médio. Portanto, estes serão utilizados para a comparação entre os períodos pré e pós-Fukushima, através do modelo original. Para este caso, os quatro grupos somam 390 questionários válidos.

Estes grupos também caracterizam indivíduos do público, e serão tomados como representantes desta classe. Os demais grupos portanto caracterizam o grupo dos especialistas. 
Já para analisar os efeitos da visita à Central Nuclear Almirante Álvaro Alberto, serão utilizados os grupos E e F.

Por fim, para a caracterizar o modelo complementar serão usados todos os questionários válidos, que perfazem um total de 463 questionários.

Considerando os modelos estruturais utilizados, a função das questões é usar dados como indicadores para mensuração das variáveis latentes.

\subsection{O modelo original}

Segue-se uma apresentação de cada variável latente utilizada no modelo original, juntamente com as questões pertinentes.

As variáveis são divididas em dois grupos: aquelas que se processam no momento da internalização da informação pelo indivíduo, a partir do momento em que essa informação é captada, e aquelas que processam no momento seguinte, da informação já internalizada até emergir em uma conclusão, que é nesse caso, a aceitação ou não de instalações nucleares.

\subsubsection{Das fontes de informação à internalização}

A apresentação das notícias a um indivíduo e sua subsequente internalização correspondem à primeira parte do modelo, e especificamente busca descrever o modo com que as notícias são internalizadas. Esse processo é dividido em dois caminhos, conforme abaixo:

a) Interação pessoal: corresponde às interações possíveis que envolvem contato pessoal direto, como associação de classes, ONGs, sindicatos, partidos políticos, clube social e/ou religioso além de contato com amigos, colegas e família. A frequência de acesso a esses ambientes será o fator constituinte de cada variável amostral (questão 1), e o conjunto destas deve ser usado para mensuração da variável latente correspondente.

b) Interação mediada: são aquelas interações que se dão por meio de um veículo de comunicação. São apresentados no questionário os seguintes casos: jornais, revistas, livros/revistas especializados, televisão, rádio e internet. Não há distinção entre o assunto tratado pela fonte de informação, apenas caracteriza-se a freqüência com que o entrevistado tem acesso a esses meios de comunicação (questão 2).

A informação internalizada é uma variável latente que representa todos os fatos absorvidos pelo indivíduo, sobre o tema "energia", exclusivamente. Esta variável é 
portanto caracterizada pela frequência com que o indivíduo têm contato com meios de comunicação que estejam informando sobre esse tema em específico (questão 3).

\subsubsection{Da informação internalizada à propensão a aceitar a energia nuclear}

A segunda parte do modelo busca descrever o processo de formação de opinião (especificamente, a propensão a aceitar energia nuclear) principalmente a partir das informações internalizadas. Nesse processo, inclui-se as experiências pessoais, que assim como as informações internalizadas, são influências externas ao indivíduo. Segue uma descrição das três variáveis consideradas para indicar a propensão a aceitar a energia nuclear no modelo original:

a) Fatores cognitivos: representam todo o conhecimento adquirido pelo indivíduo sobre energia, especialmente sobre energia nuclear. Dado que é impraticável recolher todo o conhecimento que um indivíduo tem sobre energia nuclear, pressupôs-se que a aquisição de conhecimentos pode ser rastreada através de um caminho lógico para a aceitação, que é descrito pelos seguintes pontos:

i. Percepção da necessidade de energia elétrica: deve verificar se o indivíduo reconhece a importância da energia elétrica para si e para os outros (questões 9, 10 e 11).

ii. Percepção de matriz diversificada: estando ciente da necessidade de energia elétrica, as questões correspondentes à essa variável latente buscam avaliar se o indivíduo está ciente ou não da necessidade de uma matriz de produção energética diversificada, que deve envolver, entre outras, a geração de energia elétrica através de instalações nuclear (questões 23 e 24).

iii. Percepção comparativa: entende-se que se o indivíduo reconhece a importância da energia elétrica para si e para os outros e está ciente da necessidade de uma matriz energética diversificada (itens i e ii), a aceitação da energia nuclear nessa matriz dependerá de como o indivíduo compara essa fonte de energia com as demais. A comparação deverá favorecer a energia nuclear se o indivíduo estiver ciente de fatores que predispõem e favorecem esse tipo de fonte energética. Esses são caracterizados através do reconhecimento da energia nuclear como uma fonte plausível para geração de energia elétrica (questão 25) e uma noção de sua adaptação aos recursos naturais disponíveis (questão 26). 
b) Percepção de benefícios: Corresponde à noção do indivíduo sobre os benefícios oriundos da construção de uma central nuclear, além dos usos benéficos da radiação em outras situações. Aqui, a questão 6 busca identificar a percepção da utilidade da radiação para a saúde, agricultura e indústria. A consciência de que uma usina nuclear deve trazer benefícios como aumento da oferta de empregos, crescimento do comércio, construção de estradas, escolas e hospitais é verificada na questão 8, e a questão 7 verifica a percepção declarada de benefícios de uma usina nuclear para a comunidade onde o indivíduo vive.

c) Experiência pessoal: Diferentemente dos outros dois fatores apresentados (itens a e b), esta variável estrutural não deve ter ligações com as notícias internalizadas. As circunstâncias que podem influenciar a percepção de sobre as instalações nucleares são: o conhecimento de alguém próximo que trabalha em qualquer atividade relacionada à área nuclear (questão 4) ou de alguém que tenha utilizado a radiação como tratamento de saúde (questão 5).

d) Propensão para aceitar a energia nuclear: Esta é a variável dependente do modelo. As variáveis amostrais para esse caso são a opinião expressa sobre a construção de centrais nucleares no Brasil (questão 27), a fração que esse tipo de energia deve compor na matriz energética nos próximos 30 anos (questão 28), a aceitação de usinas nucleares a até 30 quilômetros da residência do entrevistado (questão 29) e em regiões afastadas de centros urbanos (questão 30).

\subsection{Hipóteses consideradas}

Nos modelos estruturais, as hipóteses consideradas estão representadas nas setas que conectam as variáveis latentes. Conforme mencionado, o sinal de positivo indica que espera-se que cada hipótese represente uma relação positiva com as variáveis relacionadas.

a) H3a(+): Esta hipótese supõe que um aumento nas interações pessoais (diálogos) deve levar a um aumento nas informações internalizadas. Dado que o diálogo é logicamente um método de transmissão de conhecimento, esta hipótese deve confirmar a existência desta correlação e sua intensidade. Acreditando que o assunto "energia" é de interesse geral, especialmente por compor um dos gastos comuns para os cidadãos (Eurobarometer, 2008), espera-se que uma correlação perceptível sustente esta hipótese.

b) $\mathbf{H 3 b}(+)$ : De maneira semelhante, temos uma correlação positiva entre as variáveis "interação mediada" e "informação internalizada". Sendo o tema "energia" presente 
nos veículos de comunicação, em especial num momento onde há um acidente de grande notoriedade, como o de Fukushima, espera-se que o contato com fontes de informação veiculadas também apresente uma relação sólida com as informações internalizadas sobre energia.

c) H2a(+): A percepção de benefícios, para a amostra selecionada, é resultado da apresentação de informações internalizadas sobre esses benefícios. Isso ocorre porque nenhum dos entrevistados reside próximo à uma instalação nuclear, e portanto não cria as experiências diretas verificadas no questionário, nem vivencia diretamente os benefícios discutidos.

d) $\mathbf{H 2 b}(+)$ : Os fatores cognitivos são caracterizados por conhecimentos específicos referentes a um processo lógico para a aceitação da energia nuclear. Esses conhecimentos devem emergir das informações internalizadas pelo indivíduo através das fontes de informação que tratam do tema de energia.

e) H1a(+): O contato com trabalhadores de uma instalação nuclear e o contato com familiares que possam ter se submetido a tratamento por radiação pode influenciar a aceitação a instalações nucleares. Para o contato com trabalhadores, espera-se que este resulte numa aceitação da energia nuclear, considerando que há uma confiança por parte do público nesses trabalhadores (Ribeiro Jr., 2007) e que estes têm uma provável posição favorável às instalações nucleares. Já para o contato com pacientes submetidos à tratamento por radiação, os efeitos causados por essa experiência são considerados neste modelo como benéficos para a aceitação de instalações nucleares, dado que nesse caso observa-se os efeitos terapêuticos da radiação. Em todo caso, é aceitável supor que o contato com esses pacientes possa trazer um receio quanto à presença da radiação e consequente rejeição a instalações nucleares.

f) $\mathbf{H 1 b}(+)$ : Os benefícios resultantes das instalações nucleares são certamente um fator que impulsiona a propensão a aceitar instalações nucleares. A percepção de benefícios é descrita por Ribeiro Jr. (2007) como uma força direta para a aceitação, em oposição à percepção de riscos.

g) H1c(+): O reconhecimento dos fatores cognitivos deve levar a uma aceitação das instalações nucleares já que estes fatores também constituem os benefícios para uma análise do tipo custo-benefício. 


\subsection{O modelo complementar}

Por meio dos dados obtidos para a aplicação do modelo original e da importância apresentada por diversos autores para influências emocionais no processo decisório (ver introdução), decidiu-se por explorar mais este componente, acrescentando ao modelo uma variável latente que representasse especificamente as emoções.

Entre os itens escolhidos para caracterizar esta variável estão: o tamanho da participação do público na questão onde se coloca o risco, conforme percebida pelo participante (questão 12), a sua voluntariedade em se expor ou não ao perigo apresentado (questão 13) e sua confiança ou desconfiança em diferentes segmentos relacionados à composição da opinião pública (a instalação nuclear em si, responsáveis pela usina e fontes de informação, representados na questão 14).

Outros fatores são ainda a artificialidade (em oposição a um progresso natural) associada a esse tipo de energia, supondo ser esta uma característica negativa (questão 18) e a presença do medo em si (questão 22). Conforme apresentado por Slovic et. al. (2004), pode existir a associação da energia nuclear com um "sentimento" (affect) negativo. As questões 20 e 21 buscam verificar a existência dessa associação. Na questão 20, verifica-se se há algum tipo de associação desse tipo para instalações nucleares, ao apresentar uma mesma situação (um acidente onde a única consequência é uma taxa de $1 \%$ de fatalidade) e pedir que o entrevistado a classifique de acordo com sua gravidade, para diferentes fontes de geração de energia. Ora, se a consequência é a mesma, a gravidade independe da fonte de energia em questão. Atribuir gravidades diferentes evidencia um sentimento intrínseco negativo às fontes consideradas mais perigosas. Já a questão 21 pede que o entrevistado selecione, entre palavras que trazem à memória sentimentos bons ou ruins, aqueles que estão relacionados à energia nuclear (eletricidade, bomba, câncer, eficiência e explosão).

Por fim, a questão 19 considera diversas fontes de geração de energia elétrica a serem posicionadas numa escala de "péssimo" a "excelente" para distinguir se as emoções de um determinado tipo são exclusivas de um tipo de fonte.

Supõe-se que essa nova variável latente está associada ao modelo através de uma correlação direta a partir dos fatores emocionais, para a propensão a aceitar instalações nucleares. Essa hipótese será denominada H1d(+). Para que esta correlação também seja caracterizada pelo sinal "positivo", algumas questões precisaram ter seus valores invertidos, já que para estas, valores altos indicavam uma provável rejeição às instalações nucleares, diferentemente de como vinha sendo feito. Foram portanto invertidas 
as respostas das questões 15, 16, 17, 18 e 21 (nesta última somente para os itens de caráter pejorativo: Bomba, Câncer e Explosão).

Conforme apresentado anteriormente, a questão 19 trata da comparação entre as instalações nucleares e outras instalações, numa escala de "péssimo" a "excelente". Para que os dados coletados pudessem ser corretamente interpretados pelo tratamento estatístico utilizado, tratou-se de obter a média dos valores assinalados para todas as fontes de energia, exceto nuclear. $\mathrm{O}$ valor assinalado para nuclear foi então subtraído dessa média. Assim, o resultado deste processo deve representar a diferença entre o julgamento aplicado às instalações nucleares, frente à media dos julgamentos expressados para as demais fontes de energia.

Um tratamento idêntico foi realizado para a questão 20. Essa é a questão que apresenta um dado concreto, sobre um acidente idêntico para diversas usinas. A questão foi desenvolvida a partir de trabalhos elaborados por Slovic et. al., mas em um contexto diferente (Slovic et. al., 2004).

\subsection{Os modelos original e complementar, nas perspectivas de risco}

Através dos fundamentos teóricos apresentados, é possível neste momento enquadrar os modelos estruturais elaborados pelo grupo de pesquisa através de modelos tradicionais de perspectiva em risco. Três desses modelos de perspectiva podem ser representados a partir da metodologia estabelecida:

1. Amplificação social de risco: Conforme mencionado, a amplificação social busca compreender os efeitos desenvolvidos a partir da forma como as informações sobre risco são adquiridas. A primeira parte dos modelos busca caracterizar justamente os efeitos da informação, seja ela mediada por veículos de comunicação, ou por relações sociais.

2. Modelos mentais: A principal característica desse modelo é o reconhecimento de modelos de representações mentais do mundo, através dos quais emergem muitas das diferenças entre as opiniões do público e de especialistas. Dividir a elaboração da percepção de risco em uma linha de pensamento razoável, simples e lógica é uma tarefa que permite a identificação de semelhanças e divergências entre esses grupos, de acordo com suas percepções. Especificamente nos modelos elaborados, essa linha de raciocínio está presente nos fatores cognitivos, onde entende-se que um especialista esteja propenso a aceitar a energia nuclear reconhecendo a importância dos três pontos apresentados nesta variável: percepção da necessidade de energia elétrica, percepção da 
matriz diversificada e percepção comparativa. Note que essa condição, por si só, não define os especialistas.

3. Modelos psicométricos: Os modelos elaborados buscam desenhar a percepção pública a partir das opiniões declaradas, utilizando ferramentas estatísticas, sendo esta justamente a definição de modelos psicométricos. Logo, esse modelo é o que melhor enquadra o trabalho, especialmente sobre a análise dos modelos estruturais utilizados. A seguir, apresenta-se a forma com a qual foi realizado o tratamento estatístico para os modelos estruturais. Especificamente para os grupos elaborados (público e especialistas; antes e depois de visitar a central nuclear), o tratamento estatístico resume-se a uma comparação de resultados.

\subsection{Tratamento estatístico}

A análise dos dados obtidos seguiu o tratamento realizado para os dados coletados antes do acidente em Fukushima (Barroso, 2010). Esse procedimento começa com uma análise exploratória, onde o modelo original com todas as variáveis foi reduzido através de critérios de validade e confiabilidade. Embora os dados estivessem fundamentados num modelo relativamente confiável (até então ainda não testado), a amostra utilizada neste caso consiste em 209 respondentes, e esse tamanho da amostra é pequeno para utilizar modelos de equações estruturais baseados em máxima verossimilhança. Portanto decidiu-se por utilizar PLS-PM (Partial Least Squares Path Modeling, Henseler et. al., 2009). Na verdade, esse modelo utiliza um tipo de equação estrutural baseada no próprio PLS para testar o modelo final.

Especificamente no modelo estruturado, os resultados exploratórios sugeriram dividir as variáveis amostrais da interação pessoal em duas variáveis amostrais: políticoprofissionais (representada no questionário novo pela questão 1 e apenas para os itens “Associação de classe", "ONGs", "Sindicatos" e "Partidos políticos") e família-lazer (questão 1, demais itens). Para as interações mediadas, dividiu-se suas variáveis amostrais entre escrita (questão 2, para os itens "Jornais", "Revistas" e "Livros especializados") e audiovisual (questão 2, demais itens). Pelo mesmo processo, as informações internalizadas ficaram caracterizadas pelas variáveis amostrais denominadas escrita (questão 3, para "Jornais", "Revistas" e "Livros especializados"), audiovisual (questão 3, para os demais itens) e diálogos. Esses diálogos eram caracterizados por um item referente a conversas com amigos e familiares na questão 3, e não foi reproduzido no questionário novo. Conforme veremos adiante, decidiu-se por excluir esse item pois a correlação entre as 
interações pessoais e informações internalizadas vinham se mostrando desprezível. Dado o tamanho original do questionário somado à inclusão de novas questões, essa exclusão é adequada.

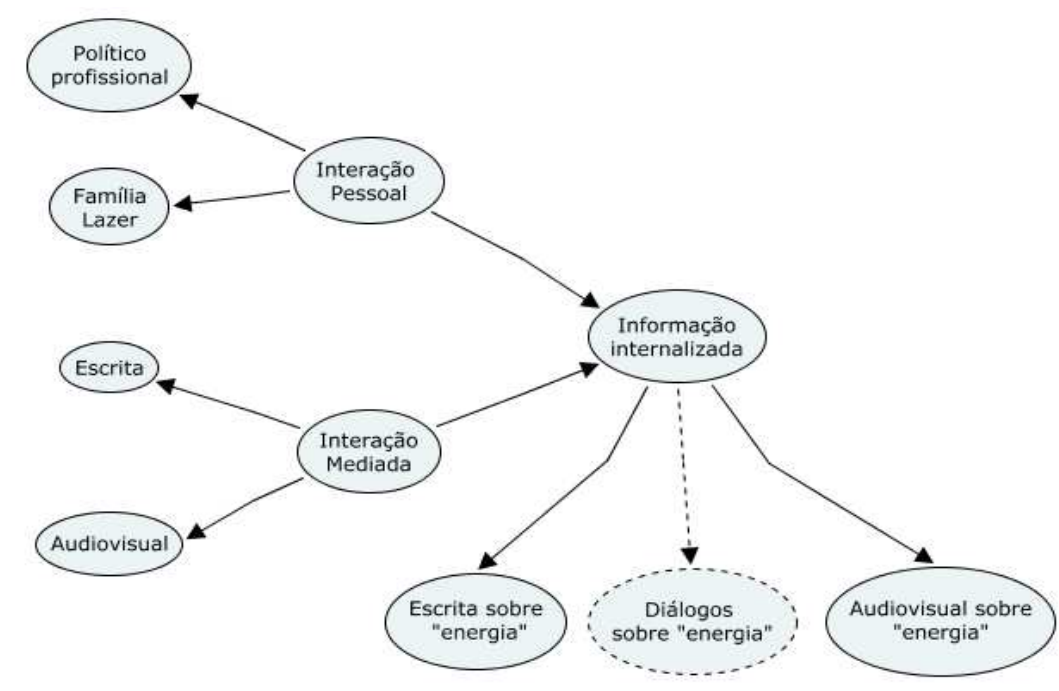

FIG. 3 - Primeira parte do modelo após análise exploratória. A linha tracejada indica a variável excluída

Com o software SmartPLS o modelo estrutural é reproduzido por meio de suas variáveis correspondentes, coeficientes de regressão padronizados referentes às hipóteses a serem testadas e respostas obtidas pelo questionário, cada qual devidamente relacionada à sua variável latente. Para que os dados possam ser adequados à este software, os mesmos foram expressos numa tabela simples de entrevistados versus respostas expressadas.

O modelo estrutural pôde ser avaliado a partir da análise estrutural da matriz de correlação das variáveis latentes, da magnitude dos coeficientes estruturais e os valores de $\mathrm{R}^{2}$. 


\section{Capítulo 5}

\section{APRESENTAÇÃO E DISCUSSÃO DOS RESULTADOS}

Os dados coletados foram concentrados numa amostra de conveniência. Logo, embora estes resultados não necessariamente caracterizem a população brasileira, estes são suficientes para a comparação de grupos de interesse, conforme mencionado. Primeiramente serão apresentados os resultados para um estudo que separa indivíduos do público de especialistas. A seguir, observamos os possíveis efeitos na percepção de risco entre os alunos que participaram de uma visita educativa à Central Nuclear Almirante Álvaro Alberto, e por fim os dados são aplicados aos modelos estruturais propostos.

\subsection{Comparação dos grupos público e especialistas}

Para esta caracterização, o tamanho das amostras se apresenta da seguinte maneira: os especialistas são compostos por 73 questionários válidos, enquanto os indivíduos do público são caracterizados por 390 questionários válidos. São considerados especialistas aqueles indivíduos que trabalham ou estudam temas ligados à energia nuclear ou à aplicação de radiação ionizante.

As questões escolhidas para esta tarefa são as mesmas que compõem as variáveis do modelo original. Questões do modelo novo, referentes à emoção associada, só serão usadas quando pertinente.

\subsubsection{Resultados e contexto}

Para os meios e os locais de comunicação e troca de informações diversas, estes dois grupos declararam que comparecem pouco aos seguintes locais apresentados no questionário: associação de classe, O.N.G., sindicato e partido político. Para todos esses 
locais, tanto para o grupo de indivíduos do público como para o de especialistas, pelo menos oitenta por cento dos respondentes declarou frequentá-los "quase nunca".

Já para os locais: clube social/religioso e encontro com colegas e família, os resultados apresentam uma frequência consideravelmente diferente. Especificamente para o segundo local, 65\% dos especialistas e 79\% dos indivíduos do público declararam utilizá-lo com frequência moderada (4 ou 5, na escala de 1 a 5). Agências de comunicação e outros interessados devem considerar o impacto que estes locais podem ter na opinião pública, enquanto outras podem priorizá-las numa estratégia para direcionar a opinião pública na maneira desejada.

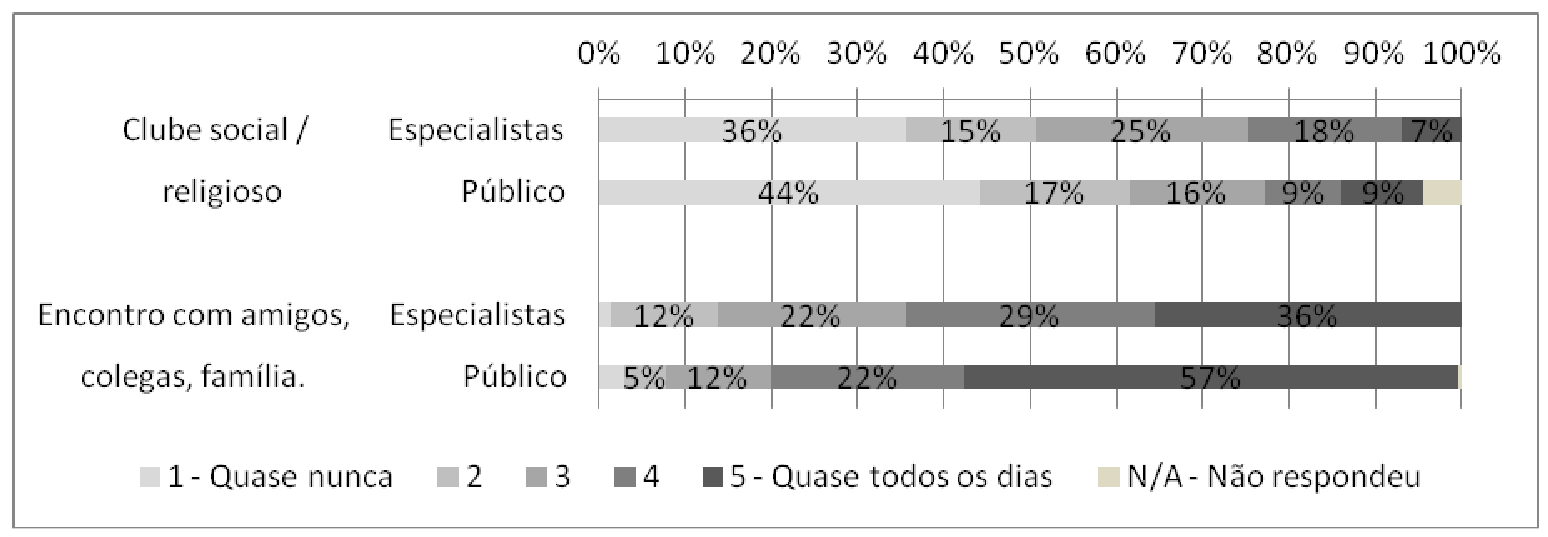

FIG. 4 - Frequência que entrevistados vão aos locais correspondentes

Já para os veículos de comunicação, especialistas, em comparação com o público, utilizam notoriamente mais jornais e livros e revistas especializados, enquanto o público apresenta uma preferência relativa maior para o rádio e a televisão. Entretanto, para ambos os casos, os veículos de comunicação mais utilizados são a televisão e a internet. A fig. 5 a seguir apresenta a proporção de entrevistados que assinalou 4 ou 5 nas frequências, para cada meio de comunicação. 


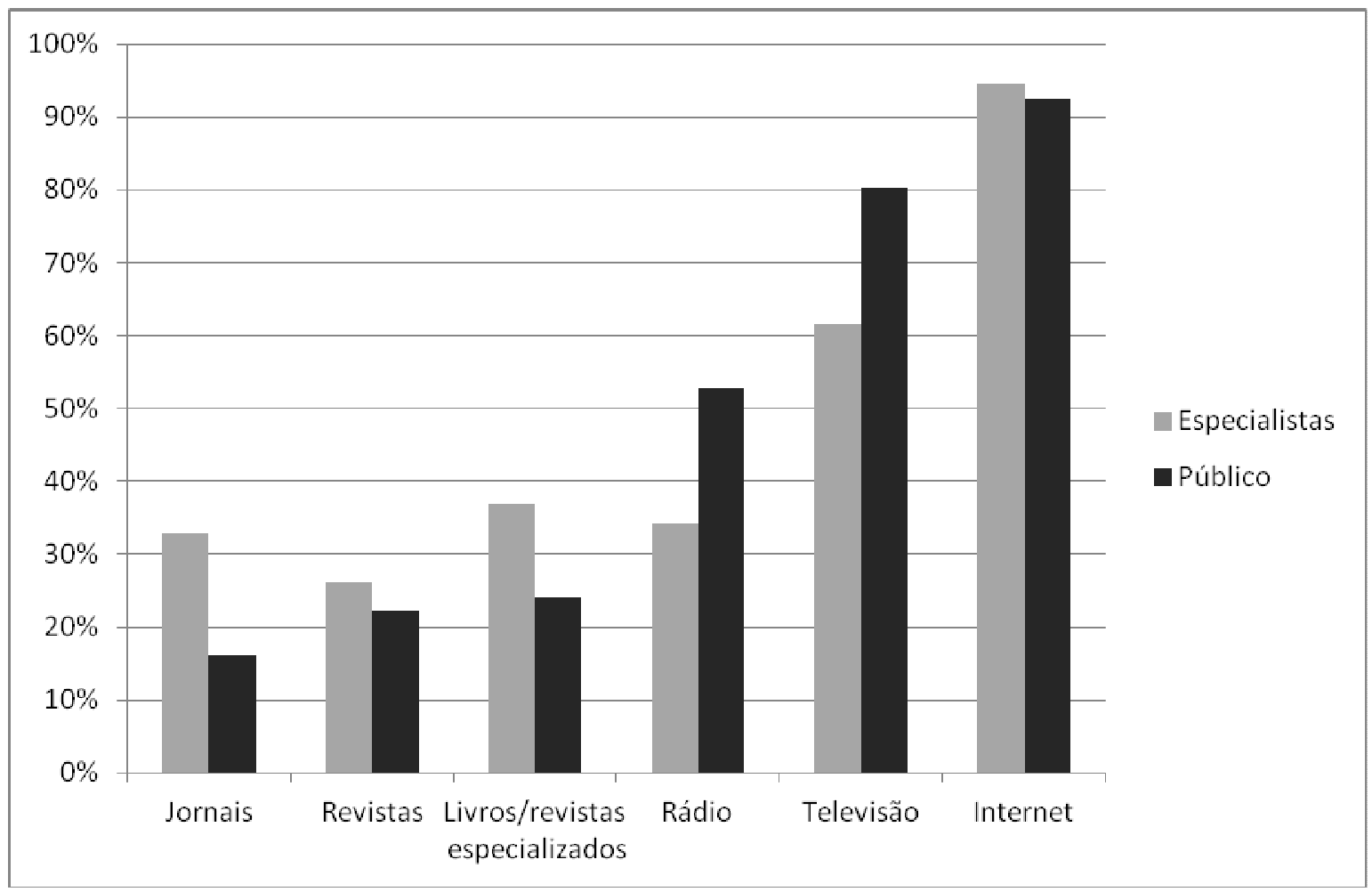

FIG. 5 - Uso dos meios de comunicação, para cada grupo

Para esses dois principais meios de comunicação, a televisão e a internet, considera-se com que frequência cada grupo se informa nestes meios especificamente sobre o tema "energia". Quarenta por cento dos especialistas declararam encontrá-lo na televisão com frequência considerável (assinalou 4 ou 5 na escala apresentada). Para os indivíduos do público consultados, essa parcela é de $37 \%$.

Os valores para cada meio de comunicação, quando divididos nos grupos propostos, podem ser apresentados numa tabela de contingência (tab. 2) . Nesta tabela são apresentadas as frequências observadas de cada resposta, para um dado meio de comunicação, além da frequência esperada para o caso de não haver correlação entre os grupos e as respostas. Essa frequência esperada é calculada utilizando como amostra os dois grupos combinados, e portanto representa a hipótese de as frequências apresentadas não serem características dos grupos (Hoel, 1981:282). 
TABELA 2 -Frequências observadas e esperadas sobre a leitura de jornais

\begin{tabular}{ccccccc}
\hline & \multicolumn{5}{c}{ Respostas* } & Totais \\
\hline Especialistas & $14(24)$ & $15(22)$ & $19(13)$ & $11(5)$ & $13(9)$ & 72 \\
Público & $141(119)$ & $123(104)$ & $61(51)$ & $21(18)$ & $42(35)$ & 388 \\
Totais & 155 & 138 & 80 & 32 & 55 & 460 \\
\hline *O número em parênteses representa as frequências esperadas para a não-correlação entre os grupos
\end{tabular}

Através do teste de qui-quadrado, podemos verificar a hipótese de as frequências apresentadas não serem características de cada grupo. Para o caso da leitura de jornais apresentado na tabela acima, temos $\chi^{2}=22,662$, cujo valor é suficiente para afirmar que a hipótese pode ser rejeitada com probabilidade $\mathrm{p}>95 \%$ (Hoel, 1981). Cálculos equivalentes foram aplicados aos demais meios de comunicação, onde livros e revistas especializados, televisão e rádio apresentaram o mesmo resultados, enquanto as revistas e a internet indicam rejeição com $\mathrm{p}=83,82 \%$ e $\mathrm{p}=44,39 \%$, respectivamente.

Podemos concluir não só que os meios de comunicação caracterizam os grupos, mas também indicam que público e especialistas se comportam de maneira semelhante quanto à frequência de uso da internet.

Para os demais casos onde esta verificação se mostrar adequada, este procedimento será reproduzido.

No caso da internet, $62 \%$ dos especialistas consultados disseram encontrar o tema "energia" com frequência considerável, contra apenas $43 \%$ do público. Para os seguintes meios de comunicação: jornais, revistas e livros e revistas especializados, o grupo do público declarou encontrar o tema "energia" com uma frequência baixa: para qualquer um destes, pelo menos $75 \%$ dos indivíduos do público entrevistados assinalaram frequências baixas (1 ou 2 no questionário).

Para livros e revistas especializados, o tema energia é mais recorrente para especialistas do que para o público: $36 \%$ dos especialistas declararam encontrá-lo com certa frequência nestes meios (assinalaram 3, 4 ou 5), contra apenas 18\% dos indivíduos do público.

Quanto às experiências pessoais, como o contato com usinas nucleares é reduzido para os indivíduos entrevistados (não residem próximos a uma instalação nuclear), foi considerado o contato com trabalhadores na área nuclear e amigos ou familiares que se submeteram a tratamento com radiação ionizante. Para especialistas, $89 \%$ 
declararam não ter contato alguém que trabalha na área nuclear, e $60 \%$ declarou não conhecer alguém de seu relacionamento que já tenha se submetido a tratamento com radiação. As porcentagens para indivíduos do público são de $95 \%$ e $58 \%$, respectivamente. Note que embora a grande maioria dos especialistas não tenha contato com trabalhadores da área nuclear, esse fato não descaracteriza o grupo. A maioria desse grupo é composta por estudantes da área nuclear, que visitavam o reator no IPEN e alunos de engenharia (55 dos 73 respondentes, ou 75\%). Certamente, em comparação com o grupo de indivíduos do público, estes possuem conhecimentos objetivos sobre o tema suficientes para a caracterização adotada. A presença desse conhecimento objetivo pode ser constatada no item seguinte.

As diferenças entre público e especialistas acentuam-se quando consideramos os itens relativos à percepção de benefícios. As questões 6,7 e 8 avaliaram a percepção de benefícios para a saúde, agricultura e indústria (questão 6), para a comunidade onde o entrevistado vive (questão 7) e para a oferta de empregos, o comércio na região, a construção de estradas e a construção de escolas e hospitais (questão 8, neste caso com cada benefício apresentado em separado).

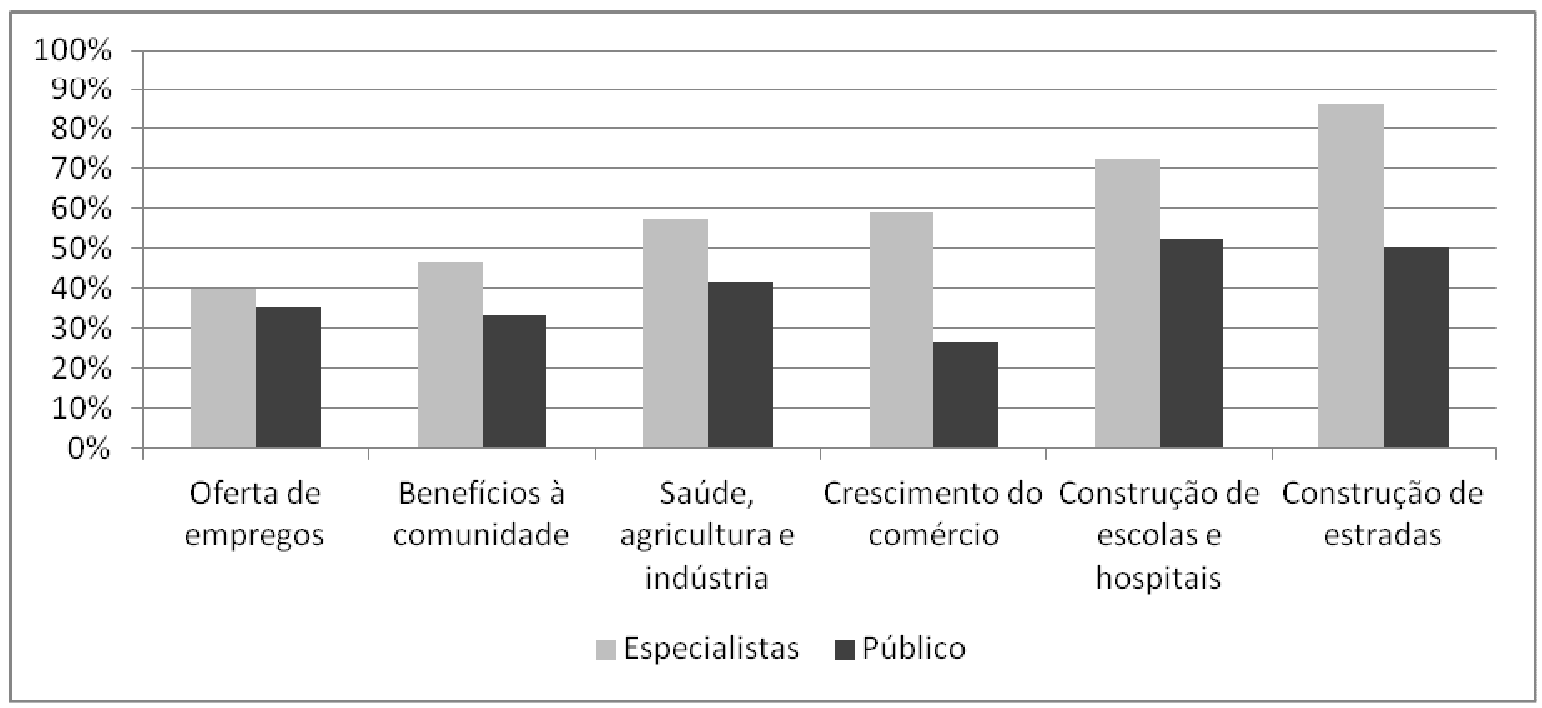

FIG. 6 - Benefícios percebidos para público e especialistas

Observe que, em relação aos benefícios apresentados, pelo menos $40 \%$ do grupo dos especialistas, em qualquer um dos itens, considera que o benefício apresentado é um dos resultados possíveis da construção de instalações nucleares. Este valor, ainda para os especialistas, chega a $86 \%$ para a construção de estradas. Para o público, a percepção desses benefícios ficou, para os diversos itens, entre $27 \%$ e $53 \%$ desta amostra. Podemos verificar a significância desses resultados através do teste de $\chi^{2}$ conforme demonstrado 
anteriormente. Nesse caso, as diferenças podem ser consideradas significativas com probabilidade $\mathrm{p}>94 \%$ para os seguintes benefícios: saúde, agricultura e indústria; benefícios à comunidade; oferta de empregos; crescimento do comércio e construção de escolas e hospitais. A construção de estradas apresentou probabilidade $\mathrm{p}=85 \%$ (Hoel, 1981).

As questões sobre a percepção da necessidade de energia elétrica, para público e especialistas, apresentaram resultados muito semelhantes, de modo que podemos concluir que ambos os grupos reconhecem a necessidade de se ter acesso à energia elétrica para si. A questão 9 avalia em quanto tempo o indivíduo se sente desconfortável no caso de uma falta de energia elétrica, enquanto a questão 10 avalia em quanto tempo o indivíduo consideraria a situação grave. As semelhanças entre os grupos nessas questões são evidenciadas no teste de $\chi^{2}$, onde as probabilidades para que os grupos sejam diferentes são de apenas $63 \%$ na questão 9 e $32 \%$ na questão 10.

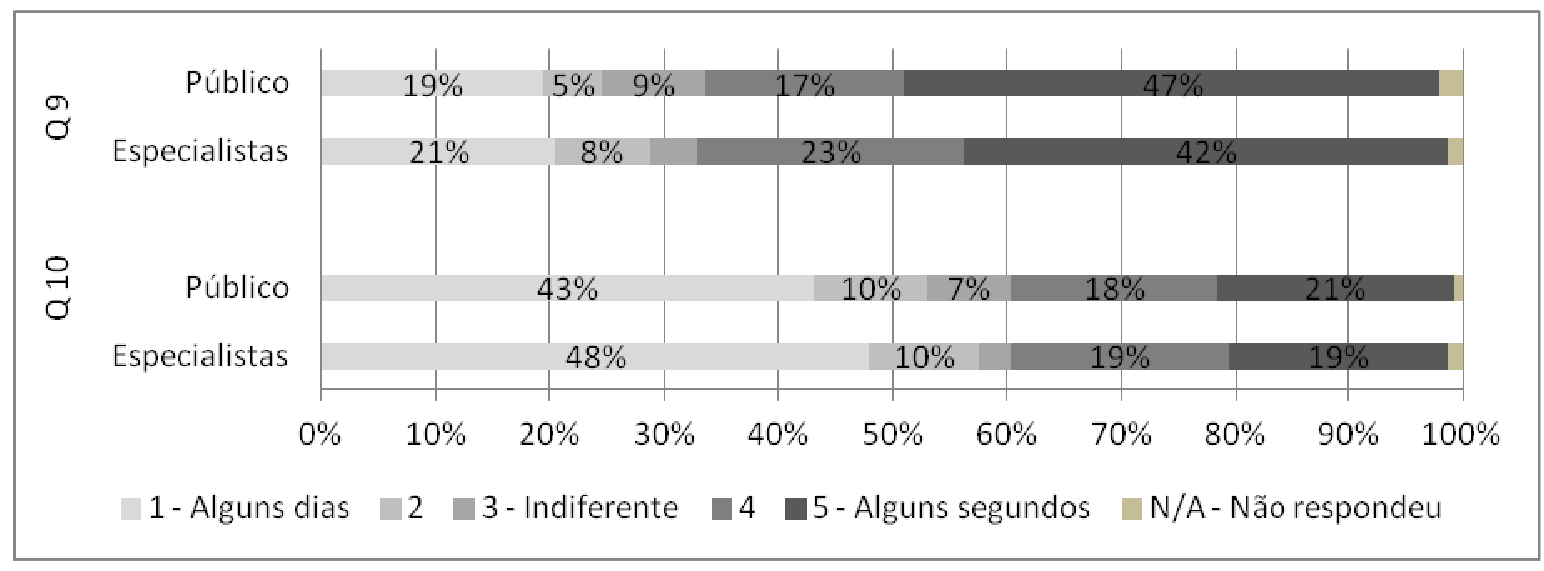

FIG. 7 - Percepção de importância da eletricidade para si.

Quanto à necessidade de se levar energia elétrica a todos os lares brasileiros, ambos os grupos são praticamente unânimes. No grupo dos especialistas, 90\% indicaram que consideram "muito importante" fazê-lo, enquanto os indivíduos do público apresentam uma parcela equivalente a $92 \%$.

Há também uma certa semelhança quando avalia-se a percepção sobre a necessidade de uma matriz energética diversficada. Esses resultados são esperados, já que as questões para esse constructo questionavam espcificamente sobre uma matriz diversificada, sem fazer referências exclusivas a fontes de energia que possuem uma percepção tradicionalmente negativa, como carvão ou a própria energia nuclear.

A questão 23 buscou avaliar se o entrevistado concordava com a necessidade do Brasil em adotar um conjunto de fontes de energia diversificado. 


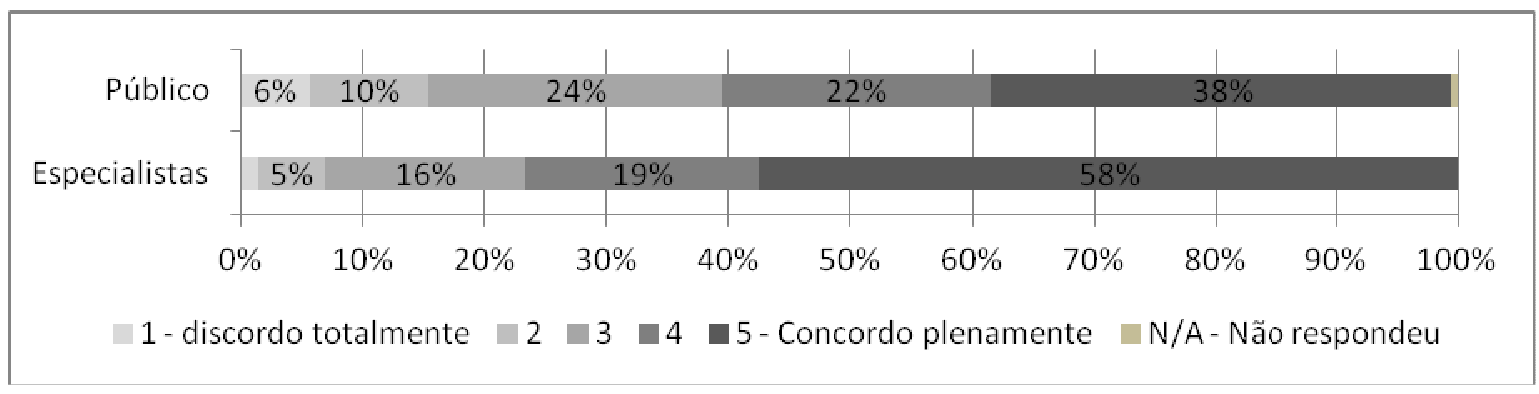

FIG. 8 - Opinião sobre a constituição de uma matriz energética diversificada.

Embora em ambos os grupos exista uma maioria que concorda sobre a necessidade de se elaborar uma matriz energética diversificada, essa tendência é mais acentuada nos especialistas Aqui, o teste de $\chi^{2}$ apresentou probabilidade $\mathrm{p}>95 \%$ para concluir que as diferenças entre os grupos são significativas.

Sobre a necessidade de se considerar os recursos disponíveis para constituir a matriz energética, essa afirmação é também bem aceita pela maioria em ambos os grupos, novamente com uma maioria mais expressiva no grupo dos especialistas. Aqui, o teste de $\chi^{2}$ indicou uma probabilidade $\mathrm{p}=74 \%$ de os grupos serem realmente distintos.

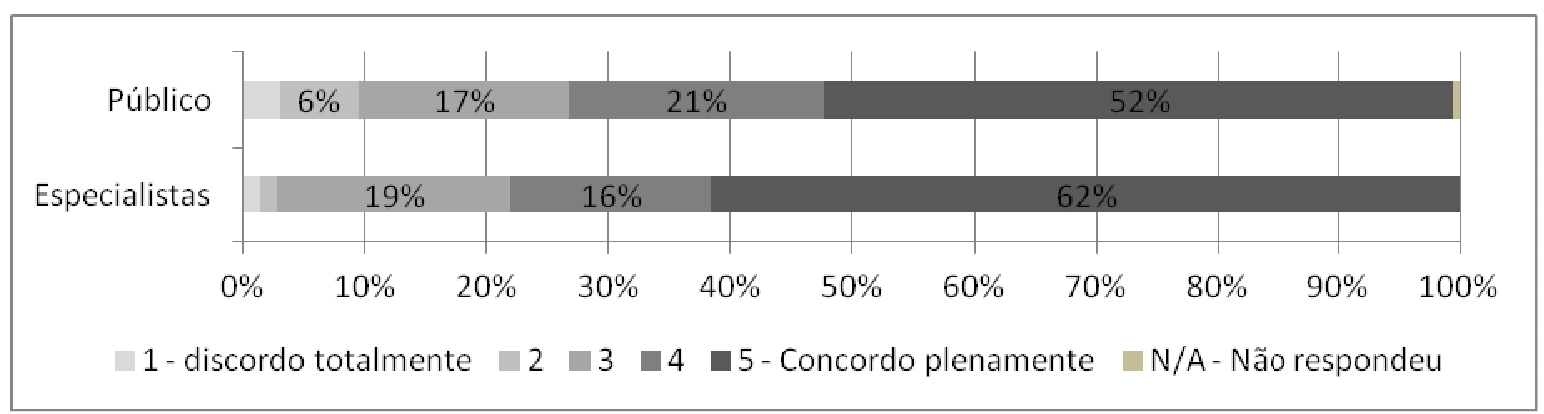

FIG. 9 - Opinião sobre a constituição de uma matriz baseada nos recursos disponíveis.

Resultados mais diferenciados são encontrados nas questões que avaliam a percepção comparativa entre fontes de energia. Como as questões para este caso apresentam e pedem que o entrevistado considere a matriz energética francesa (que é composta majoritariamente por fontes de energia nuclear), essa discrepância é esperada. Enquanto a questão 26 avalia se o entrevistado concorda com a composição dessa matriz devido às características do território francês, a questão 25 avalia se o entrevistado concorda com a atitude francesa se uma maneira geral. 


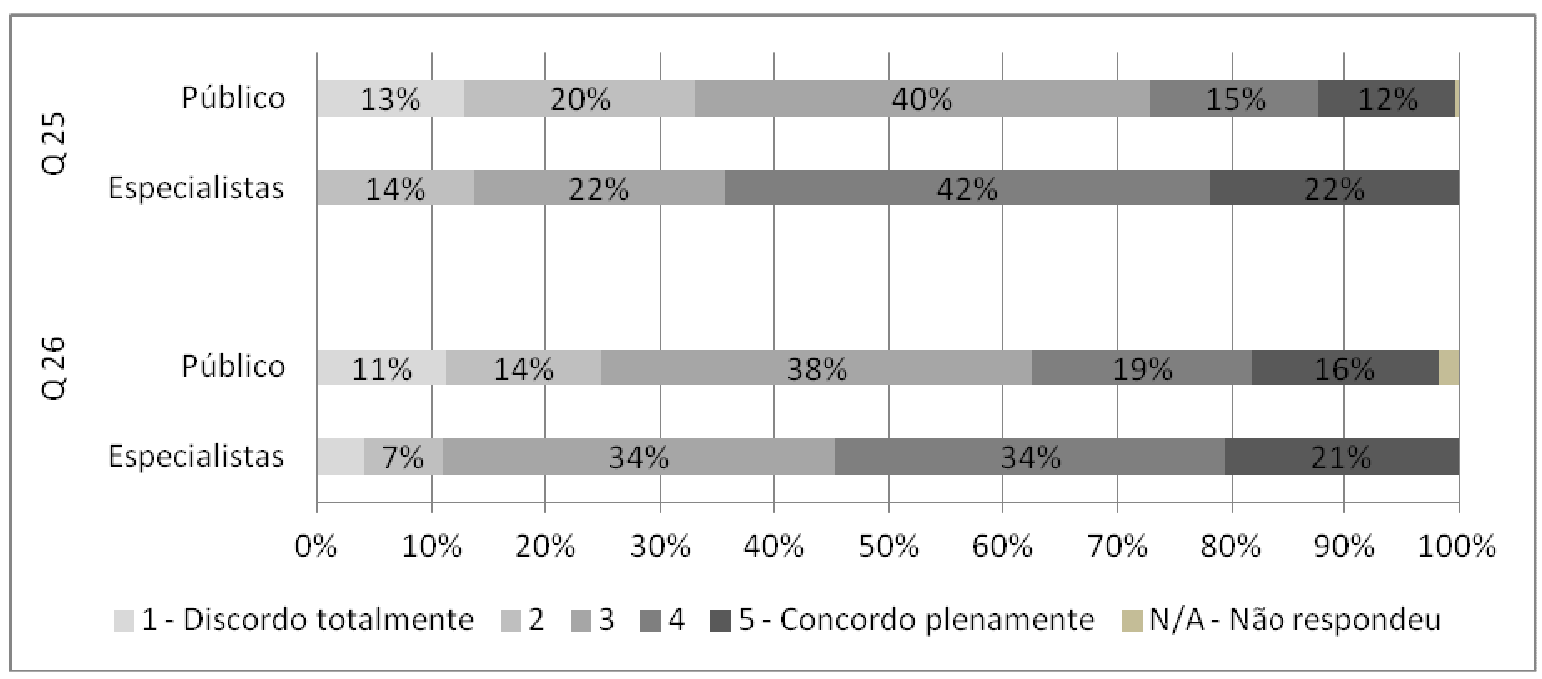

Fig 10 - Resutados das questões 25 e 26, para público e especialistas

Especialistas são mais propensos que indivíduos do público em concordar com o uso da energia nuclear na composição francesa. Observa-se que na questão 25, 64\% dos especialistas declararam concordar com tal situação (assinalaram 4 ou 5 na questão 25), contra apenas $27 \%$ dos indivíduos do público. A discrepância diminui quanto consideramos a questão 26 , onde $55 \%$ dos especialistas concordam que a decisão do franceses é boa a partir das considerações de seu território. Note que embora apenas 35\% dos indivíduos do público tenham opinião semelhante, $38 \%$ assinalaram um meio termo neste caso. Logo, uma parcela reduzida dos indivíduos do público necessariamente discorda desta afirmação (25\% do total de indivíduos do público).

Em ambas as questões, os resultados para o teste de $\chi^{2}$ apresenta probabilidade p $>95 \%$ de resultados significativos.

Finalmente, quando observamos a propensão a aceitar a energia nuclear, podemos confirmar a diferença existente na opinião entre o público e o grupo de especialistas. A questão 27, que avaliou a opinião declarada do entrevistado quanto à construção de novas instalações nucleares no Brasil obteve o seguinte resultado: 


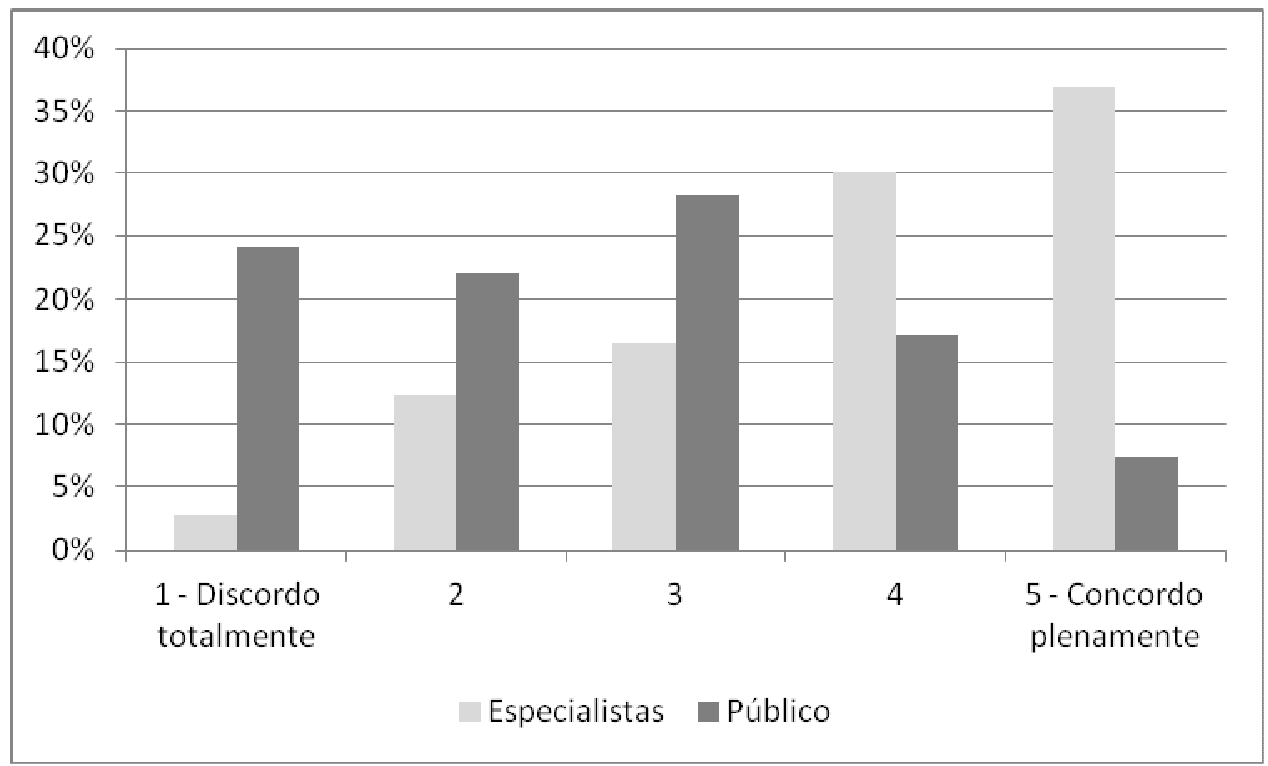

Fig 11 - Opinião sobre a construção de novas usinas nucleares.

Tanto para o grupo dos indivíduos do público como o grupo dos especialistas, a fração de respostas em branco nessa questão foi de 1\%, que não foi apresentada na figura acima. Valores de $\chi^{2}$ obtidos através da tabela de contingência indicam que os resultados são significativos com probabilidade $\mathrm{p}>95 \%$.

Quanto à participação da energia nuclear na matriz energética, os especialistas tendem a expressar uma maior preferência por esse tipo de energia. Entretanto, se considerarmos a atual composição desse tipo de energia na matriz brasileira, de 5\%, podemos concluir que a situação atual desagrada uma minoria dos dois grupos. Apenas 14\% dos indivíduos do público preferem uma participação nuclear menor que a atualmente praticada no país.

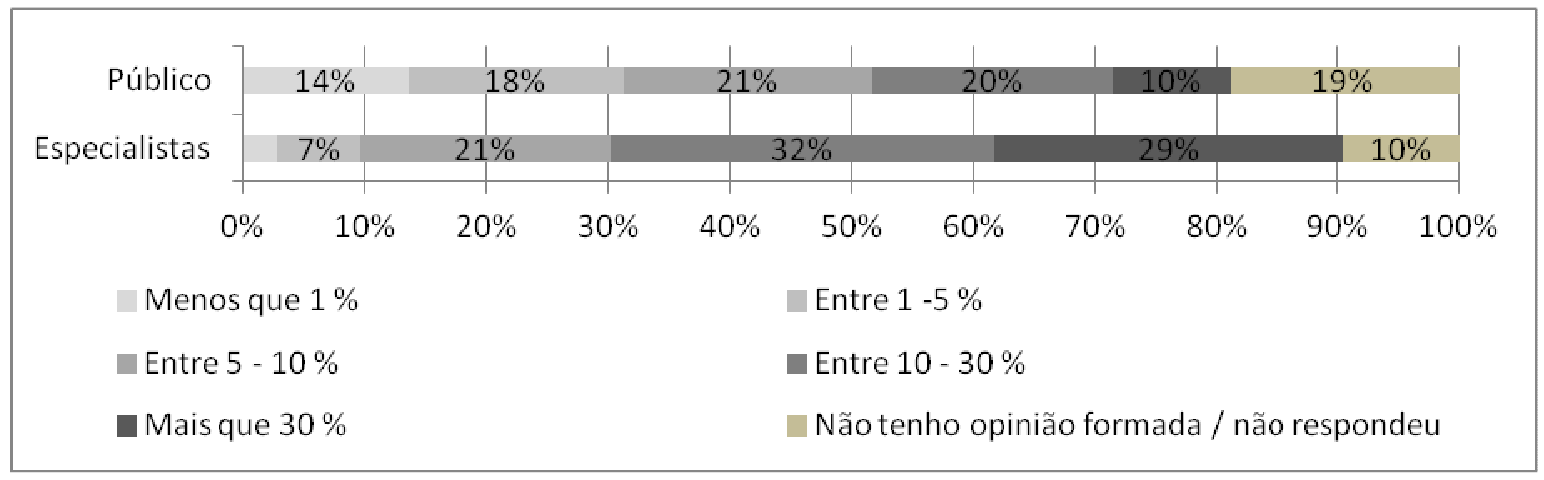

FIG. 12 - Fração adequada da energia nuclear na matriz brasileira, para os entrevistados

Observa-se também que cerca de 1 em cada 5 indivíduos do público não tem opinião formada, e que $61 \%$ dos especialistas sugerem uma participação de mais de $10 \%$ 
da energia nuclear na matriz, contra $30 \%$ dos indivíduos do público. A consistência dos resultados no teste de $\chi^{2}$ é dada com probabilidade $\mathrm{p}>95 \%$.

As duas últimas questões procuraram entender a aceitação das instalações nucleares em relação a sua localização geográfica. A questão 29 procurou avaliar se os entrevistados concordavam com instalações nucleares mesmo que próximas a suas residências, e a questão 30 procurou avaliar se estas são aceitáveis se distantes de centros urbanos.

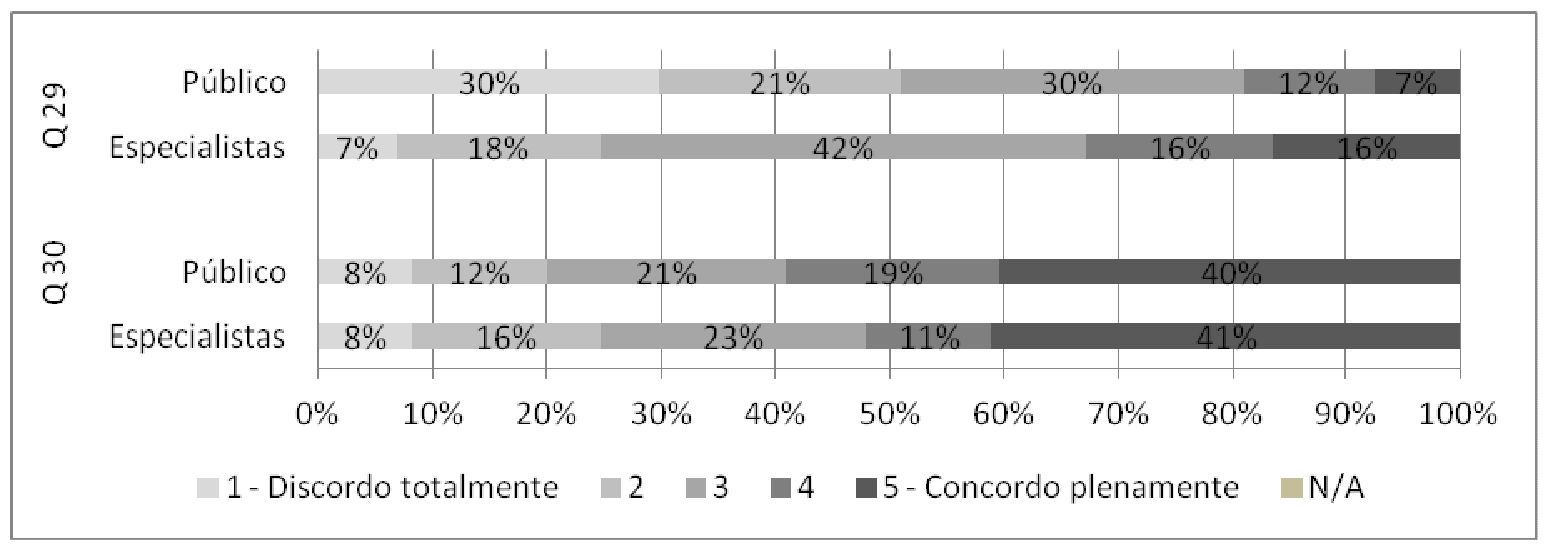

FIG. 13 - Resultados para as questões 29 e 30

Na questão 29, observamos uma parcela considerável dos especialistas que indicaram não concordar ou discordar da construção de instalações nucleares nas condições apresentadas (42\% dos respondentes). Entretanto, para este grupo, $25 \%$ dos entrevistados demostraram algum tipo de discordância, enquanto que para o público, esse valor sobe para $51 \%$. Para esta questão, o teste de $\chi^{2}$ apresentou consistência dos grupo com $\mathrm{p}>95 \%$, enquanto que na questão 30 o teste apontou consistência com probabilidade de apenas 49,77\%, indicando que os resultados são muito semelhantes e não caracterizam diferenças nos grupos propostos.

\subsubsection{Discussão dos resultados}

Os resultados indicam que os principais meios de comunicação com o público são os encontros com amigos, colegas e familiares, seguidos pelo rádio, a televisão e a internet. Especialistas possuem preferências semelhantes, mas particularmente encontram um canal melhor que o rádio nos livros e revistas especializados. As preferências sobre as fontes indicam uma caracterização aceitável dos grupos apresentados, já que o grupo dos especialistas possui maior preferência por livros e revistas especializados. Supõe-se que especialistas possuem um conhecimento objetivo sobre as instalações nucleares, o que os 
leva a aceitar melhor essa fonte de energia, embora reconheça-se que mesmo nesse grupo existem opiniões opostas quanto ao uso de instalações nucleares (Williamson \& Weyman, 2005).

A internet não só é o principal veículo de comunicação do público, como também o que mais apresenta o tema "energia" em seu conteúdo. Observando que o grupo de indivíduos do público é constituído por jovens estudantes do ensino médio, esse resultado é pertinente e sugere que a internet é um veículo importante para trabalhar a opinião pública especialmente para as gerações futuras, seguido pela televisão e pelo rádio. Porém, é importante ressaltar que a internet possui desafios diferentes, pois é um meio de comunicação mais ativo do que o rádio e a televisão.

As experiências diretas com o elemento de risco são pequenas, mesmo quando considerados elementos semelhantes. A principal fonte de informações para os dois grupos são certamente as experiências e informações mediadas.

A percepção de benefícios reforça a distinção adequada entre público e especialistas. Especialistas estão mais cientes que indivíduos do público acerca dos benefícios que uma instalação nuclear pode trazer. Também percebem melhor os benefícios da radiação em outros campos de aplicação. Embora em alguns casos a percepção dos especialistas seja consideravelmente baixa (apenas $40 \%$ dos especialistas indicaram acreditar que a construção de usinas nucleares possa trazer mais empregos), essa percepção é notoriamente maior que a dos indivíduos do público. Sabe-se que a percepção de benefícios afeta a percepção de riscos, de modo que quanto mais se percebe benefícios, menos são percebidos os riscos (Ribeiro Jr., 2007).

Os constructos sobre a percepção da necessidade de energia elétrica, percepção de uma matriz diversificada e percepção comparativa são parte de um raciocínio que pode levar à aceitação das instalações nucleares, conforme foi apresentado na seção 4.2.2.

Para a percepção sobre a necessidade de energia elétrica, ambos os grupos estão cientes da importância da energia elétrica para si, e certamente ambos concordam com a necessidade em levar esse tipo de energia para todos os lares brasileiros.

Já para o uso de uma matriz diversificada, indivíduos do público parecem concordar que matriz deva ser adequada para o território onde ela se desenvolve, mas parecem indicar que uma matriz diversificada não necessariamente seja o caso do Brasil.

As diferenças se intensificam finalmente na percepção comparativa, onde o público parece rejeitar o uso de instalações nucleares especialmente se este tipo de energia 
não é o resultado de uma necessidade desenvolvida a partir dos recursos naturais disponíveis.

Observa-se portanto que as linhas de raciocínio entre especialistas e público divergem sobre a necessidade que o país tem em compor uma matriz energética diversificada. O público, embora reconheça que a energia elétrica é um bem precioso, acredita que este pode ser obtido utilizando outras formas de energia que não a nuclear. Essa questão será retomada a partir da discussão dos resultados obtidos na questão 28.

Considerando a propensão a aceitar a energia nuclear, é possível afirmar que os grupos apresentam as características tradicionalmente esperadas, onde os especialistas tendem a ser mais favoráveis a esse tipo de energia.

É interessante observar que, embora os especialistas sejam favoráveis à construção de instalações nucleares, esse grupo não se mostrou absolutamente certo em relação à construção destas próximas a centros urbanos. De fato, a maioria expressou incerteza quanto a sua opinião nessa situação. Provavelmente, fatores emocionais associados à recente tragédia em Fukushima explicam esse resultado. Podemos analisar os resultados da questão 22, que perguntava se a existência de instalações nucleares trazia medo ou tranquilidade, para o grupo dos especialistas.

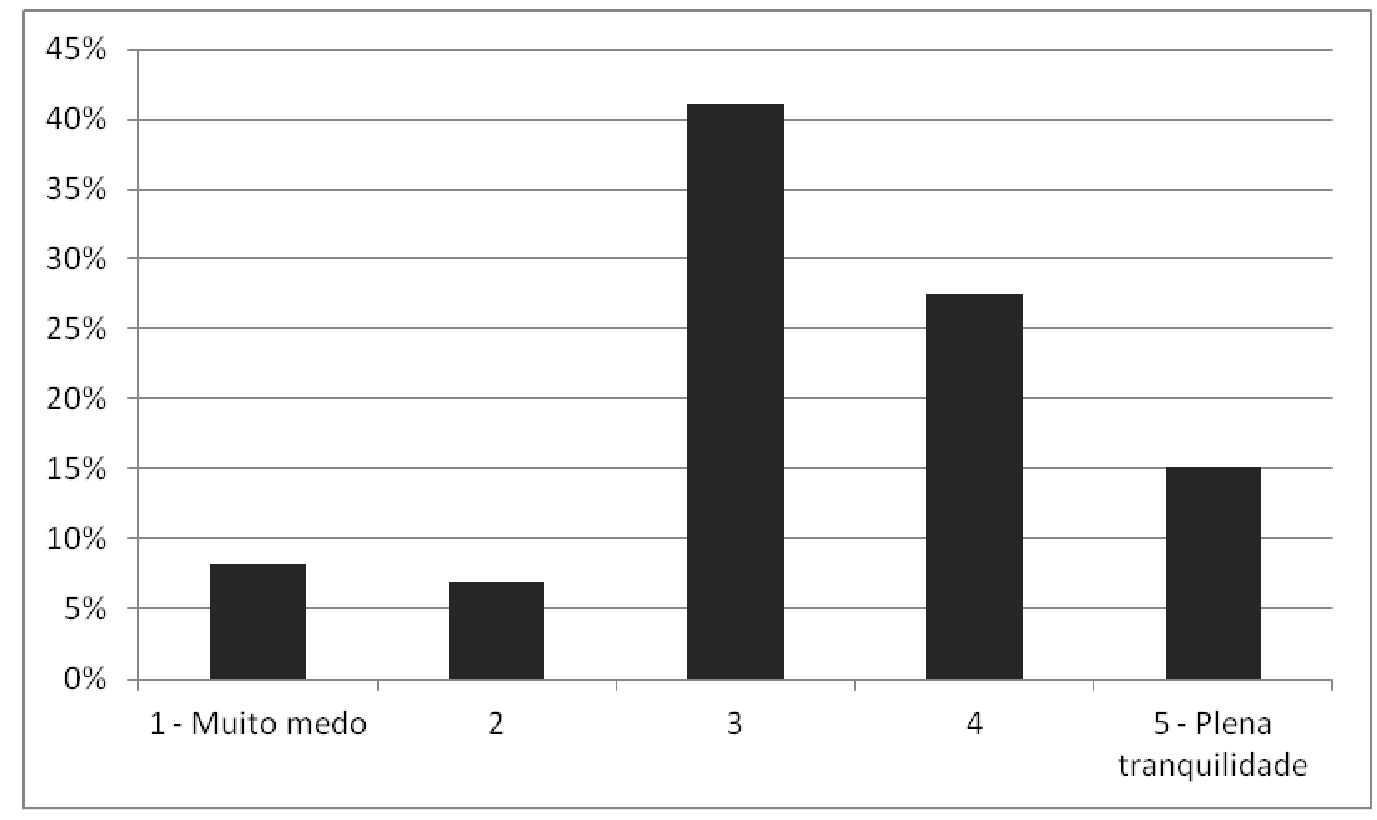

FIG. 14 - Sensação sobre a existência de centrais nucleares, para especialistas

Observamos portanto que embora os especialistas se sintam relativamente seguros quanto à existência de centrais nucleares, esta não é uma característica de todos eles, muito menos uma tendência absoluta. $41 \%$ dos entrevistados nesse grupo assinalaram 
um meio termo entre "muito medo" e "plena tranquilidade". A influência das emoções nos especialistas é uma característica notável, e que de acordo com Barke et. al. (1997), possui influências maiores do que se acreditava.

A questão 28, conforme mencionado, indica que a maioria dos indivíduos do público, embora desfavoráveis às instalações nucleares, aceitam uma participação pequena desse tipo de instalação na matriz brasileira. Essa informação não necessariamente contradiz os resultados indicados nos constructos sobre a constituição da matriz energética. $\mathrm{Na}$ verdade, podemos concluir que esses indivíduos consideram a construção de novas instalações nucleares como uma expansão destas na matriz energética, quando na verdade, o que ocorre atualmente é uma manutenção de sua participação: a construção atual de novas usinas nucleares no Brasil acompanha o crescimento da demanda por energia elétrica no país.

\subsection{Comparação dos grupos de alunos antes e após visita à usina nuclear.}

É possível comparar as respostas obtidas pelos dois grupos e observar se há uma diferença correspondente aos efeitos de uma visita educativa à usina nuclear. Os grupos são caracterizados por 103 alunos do primeiro e segundo ano do ensino médio da escola de aplicação da Universidade de São Paulo, que ainda não participaram de uma visita promovida pela própria escola à usina nuclear de Angra dos Reis. O outro grupo é composto pelos 55 alunos do terceiro ano do ensino médio que já participaram da visita. Serão analisadas apenas questões que possam indicar algum tipo de efeito na percepção de risco pelos alunos. São essas as questões que descrevem a percepção de benefícios, a presença de medo ou "tranquilidade" diante da existência de centrais nucleares e a aceitação desse tipo de energia.

Primeiramente, apresentam-se alguns resultados referentes à percepção dos benefícios, comparando os dois grupos. Assim como foi feito para a comparação entre os dados de público e especialistas, o teste de $\chi^{2}$ aplicado através de uma tabela de contingência pode permitir avaliar se os resultados são estatisticamente significativos. A figura a seguir ilustra a porcentagem de alunos que assinalaram "4" ou "5", quando questionados sobre a percepção de cada benefício. 


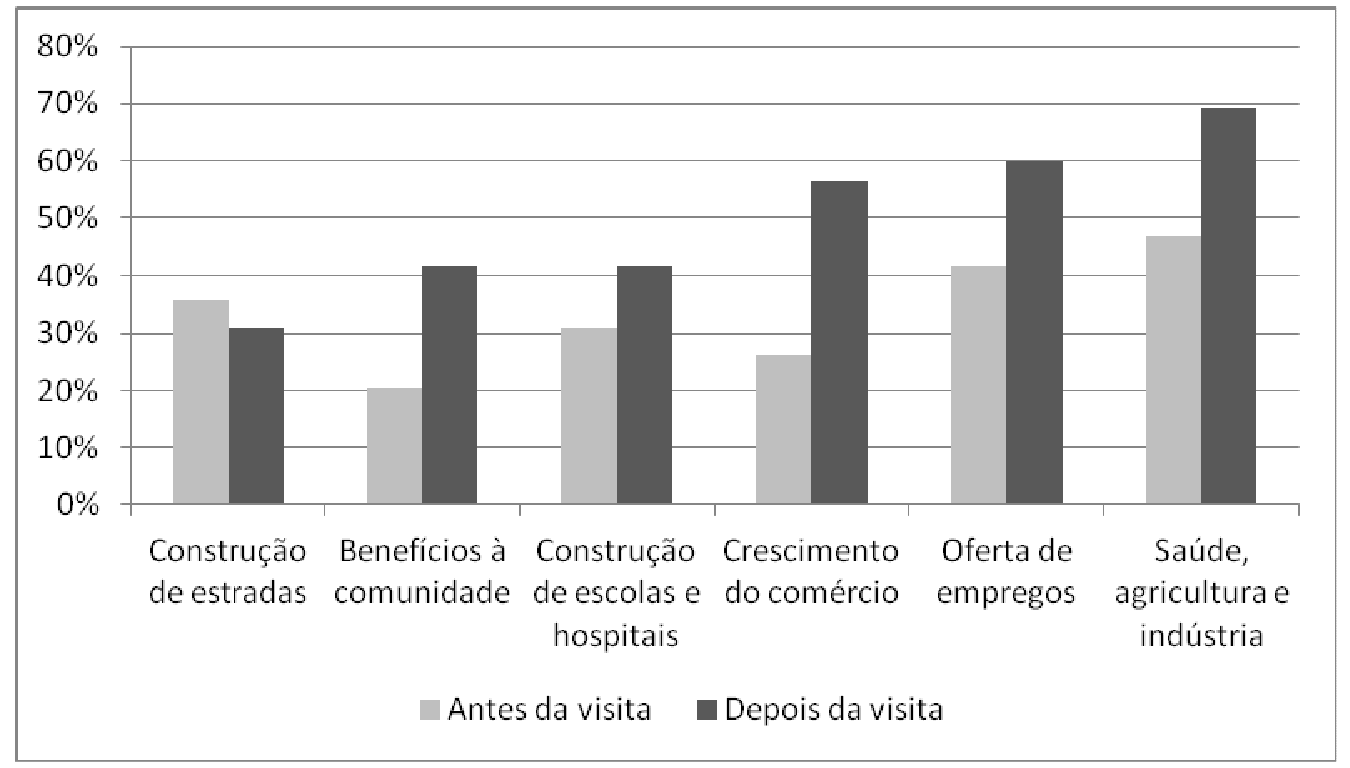

FIG. 15 - Percepção dos benefícios, antes e depois da visita

Nesses resultados, o valor de $\chi^{2}$ foi calculado para cada benefício individualmente. Para o benefício "construção de escolas e hospitais" obteve-se a probabilidade $\mathrm{p}=59 \%$ de realmente haver alguma diferença estatisticamente significativa entre os grupos. Para o benefício "saúde, agricultura e indústria", temos $\mathrm{p}=86 \%$, para os benefícios "aumento de empregos" e "construção de estradas" temos $p=92 \%$ e $p=93 \%$ respectivamente, e para os demais temos $\mathrm{p}>95 \%$. Note que o benefício "construção de estradas" têm uma percepção inferior para alunos após a visita. Este certamente é o benefício menos evidente, pois é resultado da preparação de um plano de fuga para a região, no caso de um acidente. A probabilidade apontada pelo teste de $\chi^{2}$ indica que os alunos que visitaram a usina não foram informados sobre isto e não consideraram esse raciocínio, ou o benefício de fato não existe.

Em seguida, podemos observar os resultados da questão 22, que pede que o respondente indique se tem medo ou não da existência de instalações nucleares. Os resultados parecem indicar uma pequena diferença entre os dois momentos. O teste de $\chi^{2}$ neste caso apresentou probabilidade $\mathrm{p}=43 \%$ de as diferenças serem estatisticamente significativas. Logo, podemos concluir que estas diferenças não são significativas. 


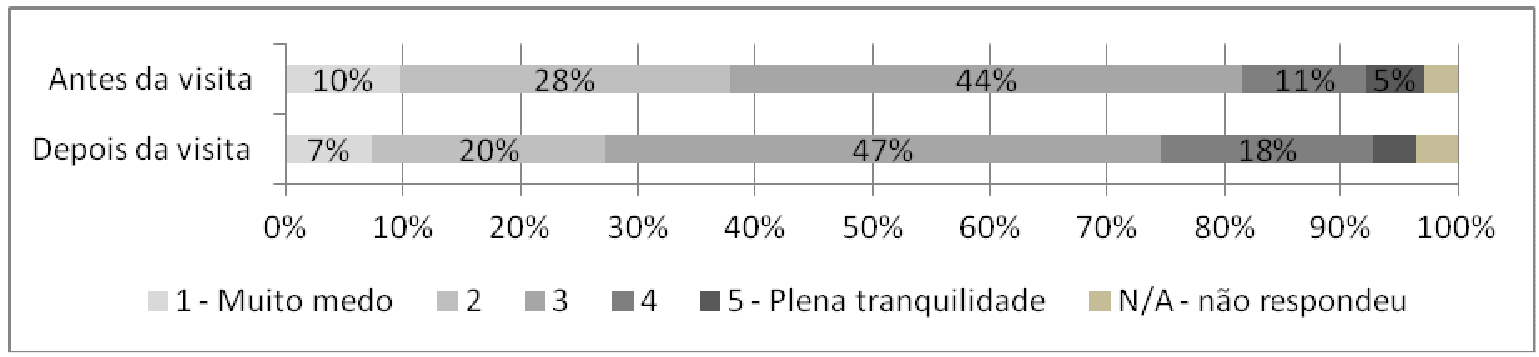

FIG. 16 - Resultados para os grupos sobre a sensação que as instalações nucleares trazem

Finalmente, comparamos os constructos referentes à propensão a aceitar instalações nucleares. Para a questão 23, sobre a opinião do entrevistado acerca a construção de novas instalações nucleares, observou-se uma diferença considerável. Notase que o percentual de alunos que tendem a aceitar a construção de novas instalações (respostas 4 ou 5 no questionário) passou de 18\% para 38\%. Observa-se que em ambos os grupos uma fatia relativamente pequena de alunos afirmara concordar plenamente com essa atitude, já que o percentual para o item 5 manteve-se baixo e não apresentou mudanças significativas (passou de $6 \%$ para $7 \%$, apenas). Não houve um número significativo de respostas em branco. $\mathrm{O}$ teste de $\chi^{2}$ indica probabilidade $\mathrm{p}=82 \%$ de os resultados serem significativos.

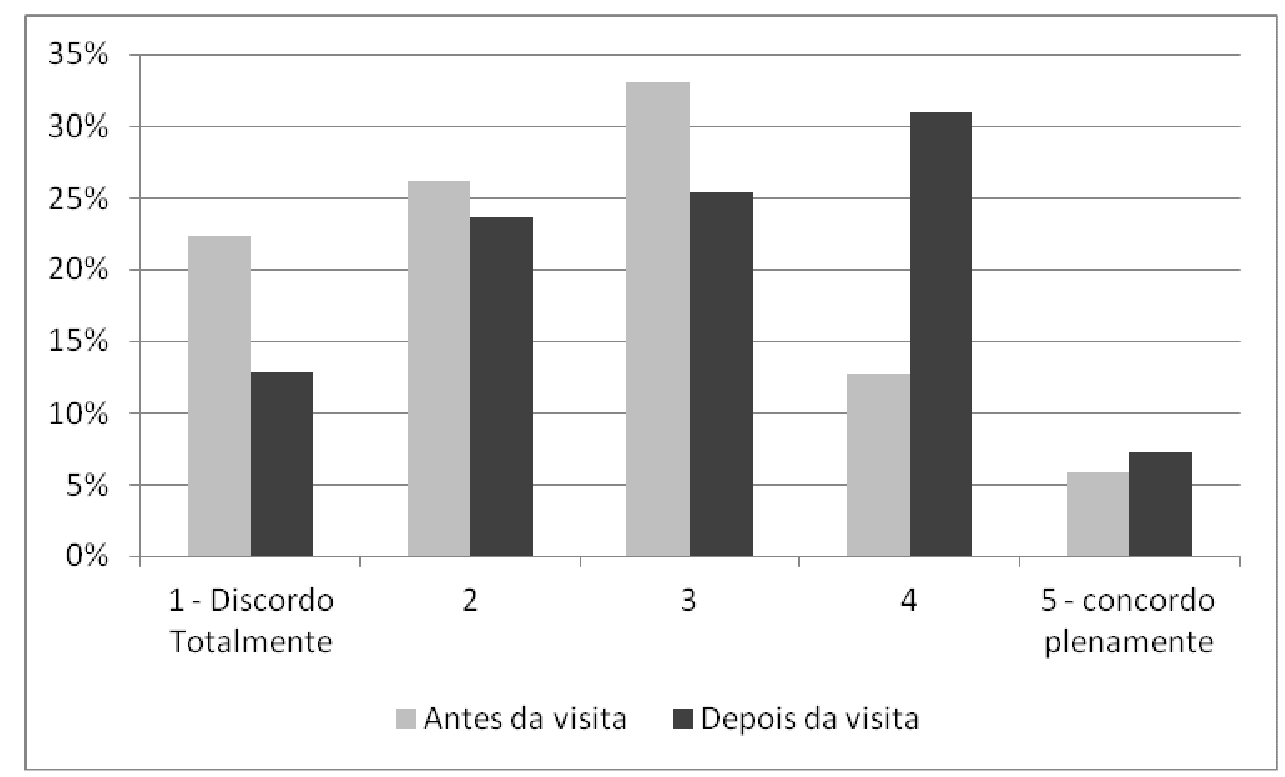

FIG. 17 - Posição sobre a construção de novas usinas nucleares no Brasil

As questões 29 e 30, apresentam os resultados para a aceitação de instalações nucleares próximas ao local onde o entrevistado reside e longe de centros urbanos, respectivamente. Os grupos considerados apresentaram diferenças discretas. Os valores, embora tenham sempre seguido um aumento na aceitação de instalações nucleares, são 
insuficientes para que se possa identificar uma mudança sólida ou permanente na percepção desses entrevistados. O teste de $\chi^{2}$ apresentou, para as questões 29 e 30, as seguintes probabilidades para diferenças estatisticamente significativas: $61 \%$ e 57\%, respectivamente.

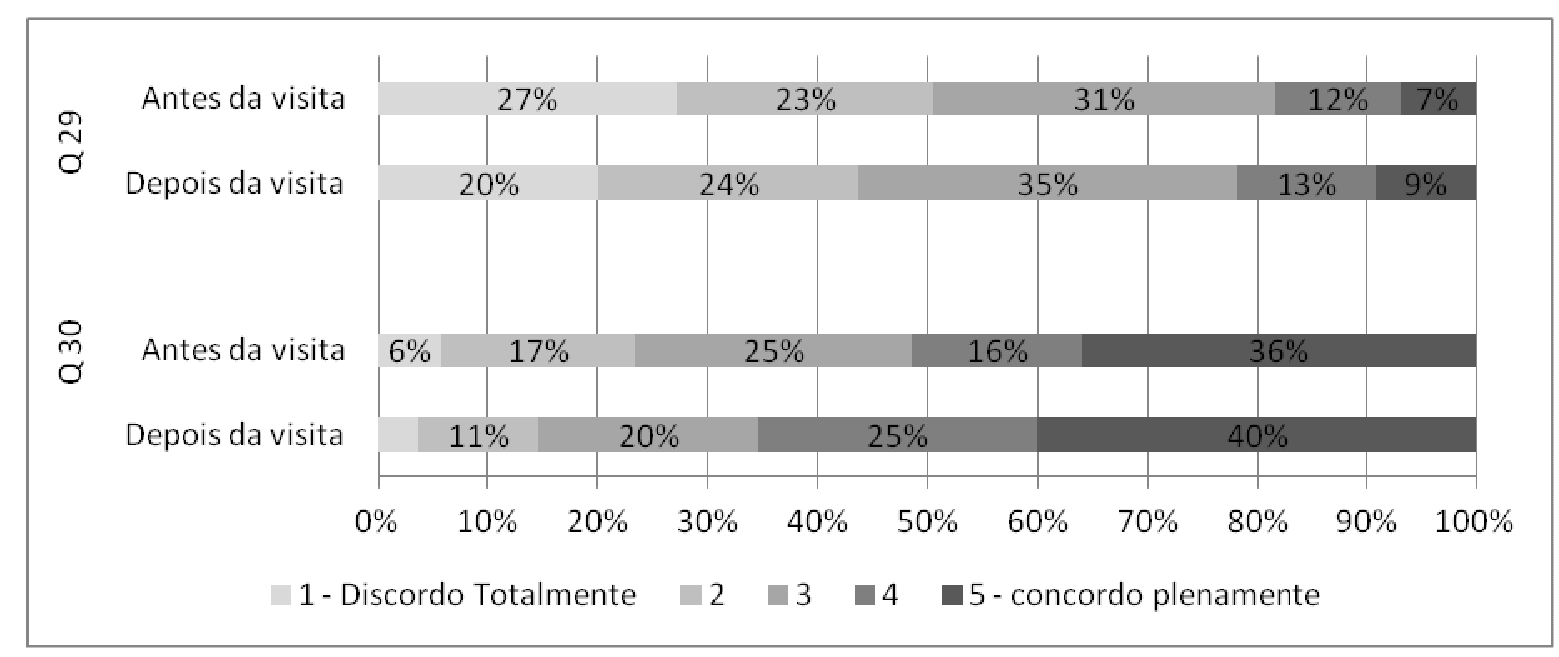

FIG. 18 - Respostas para os grupos de acordo com as questões 29 e 30

Através dos dados obtidos, podemos pressupor que a visita parece apresentar um efeito positivo na perceção das instalações nucleares, especialmente quanto à percepção de benefícios, onde em alguns casos há uma diferença estatisticamente significativa entre os dois momentos. Há uma diferença considerável no modo como os alunos declararam sentir medo, embora o teste de $\chi^{2}$ indique uma consistência baixa entre essas diferenças.

Os resultados compreendem uma amostra relativamente pequena e portanto as diferenças podem perder significado, assim como diminui a eficiência do teste de $\chi^{2}$. De qualquer modo, esses resultados bem como os apresentados para a aceitação das instalações nucleares, e em especial àqueles das questões 7,8 e 23 indicam que a visita pode aumentar a percepção de benefícios e a aceitação das instalações nucleares, mas é insuficiente para realizar essa tarefa sozinha.

A seguir, temos os resultados para o tratamento estatístico aplicado aos modelos estruturais apresentados. Esses resultados serão divididos entre aqueles obtidos a partir do modelo original (onde faz-se a comparação entre os dados antes e depois de Fukushima), e os resultados para o modelo complementar. 


\subsection{Resultados e análise dos modelos}

\subsubsection{Modelo original}

A tabela apresentada no APÊNDICE D apresenta os valores da variância média extraída para as variáveis latentes de primeira ordem. Essa variância média extraída (Average Variance Extracted, AVE) apresentou valores entre 0,42 e 0,77. Segundo Fornell (1981) recomenda-se valores maiores que 0,5.

A validade discriminante do modelo pode ser confirmada quando observamos as cargas fatoriais cruzada entre variáveis não-correlacionadas. Essas cargas são sempre menores do que as cargas apresentadas para as variáveis que estão relacionadas. Ainda, o valor da raiz quadrada da AVE para uma determinada variável latente é maior do que a correlação entre a variável latente considerada e qualquer outra variável latente.

A confiabilidade composta (Composite Reliability, CR) apresentou valores entre 0,70 e 0,89 (APÊNDICE D) Fornell (1981) e Chin (1999), recomendam-se valores iguais ou superiores a 0,70 . Os valores para os coeficientes de caminho (coeficiente de regressão padronizado entre as variáveis latentes, representando as hipóteses testadas) e os valores de $\mathrm{R}^{2}$ (que expressam a fração do variável latente que é explicada pelo modelo em questão) são apresentados na fig. 5.

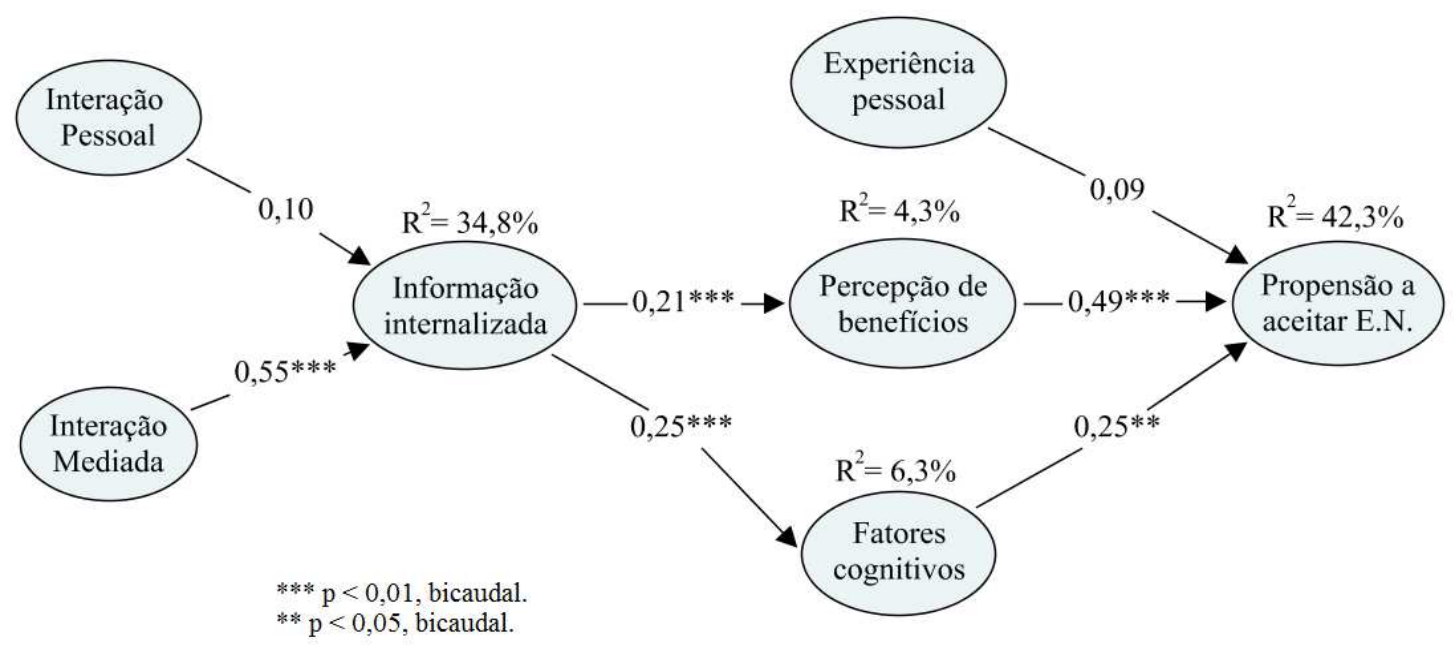

Fig. 5 - Modelo estrutural original para dados pré-Fukushima

Para os dados coletados após o acidente em Fukushima, os resultados estão apresentados no APÊNDICE E, onde o valor de AVE apresentou-se entre 0,45 e 0,78 e a confiabilidade composta atingiu valores entre 0,64 e 0,87 , exceto para a variável 
“experiência anterior”, que apresentou o valor 0,43. Esse último resultado será comentado na próxima seção.

De mesmo modo, as cargas fatoriais cruzadas para variáveis não-relacionadas entre si, são sempre menores do que as cargas apresentadas para as variáveis que estão verdadeiramente relacionadas, e o valor da raiz quadrada da AVE para uma determinada variável latente é maior do que a correlação entre esta variável latente e qualquer outra.

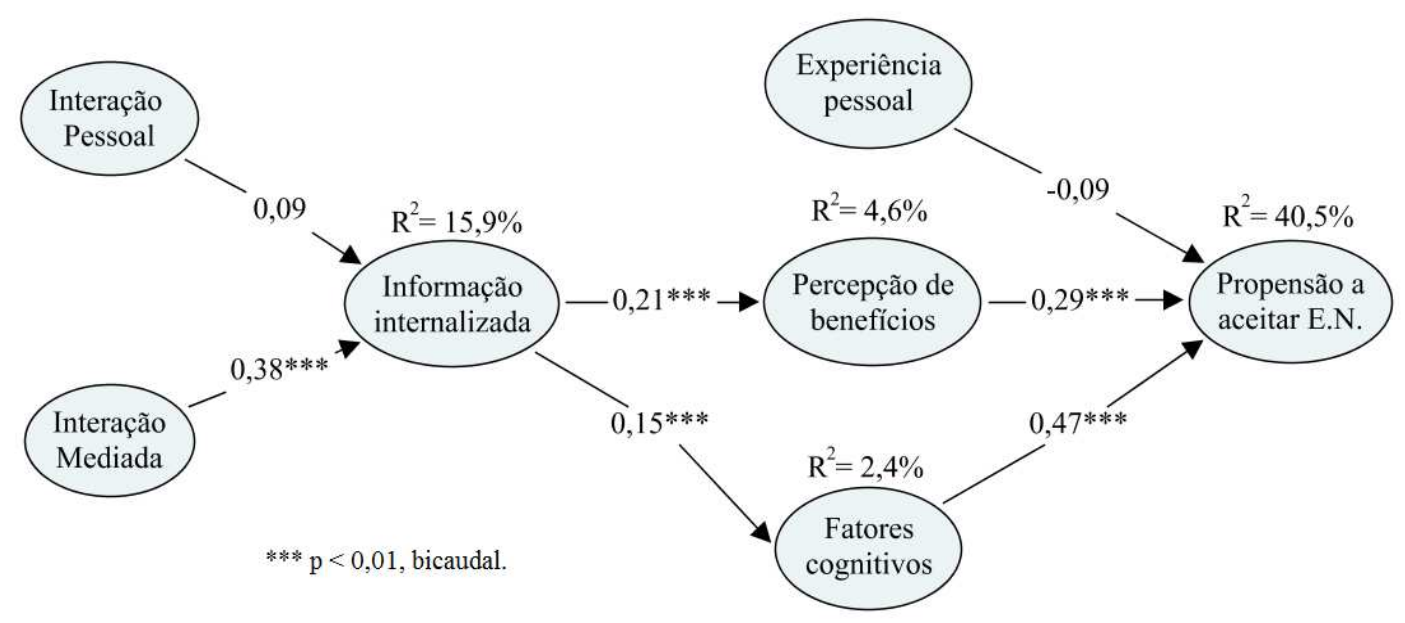

Fig. 6 - Modelo estrutural original para dados pós-Fukushima

\subsubsection{Modelo complementar}

Conforme mencionado, o modelo complementar incluiu a variável "fatores emocionais". Os resultados para a AVE e para a confiabilidade composta são expostos no APÊNDICE F e G e variaram entre 0,45 e 0,85 , enquanto os valores para confiabilidade composta ficaram entre 0,67 e 0,91, excluindo a variável latente "experiência pessoal", que apresentou confiabilidade composta igual a 0,41 , resultado que também será comentado na seção seguinte.

Os mesmos testes para as cargas fatoriais cruzadas e comparação da raiz da AVE com outras cargas fatoriais foram aplicados, ambos não apresentando inconsistências. 


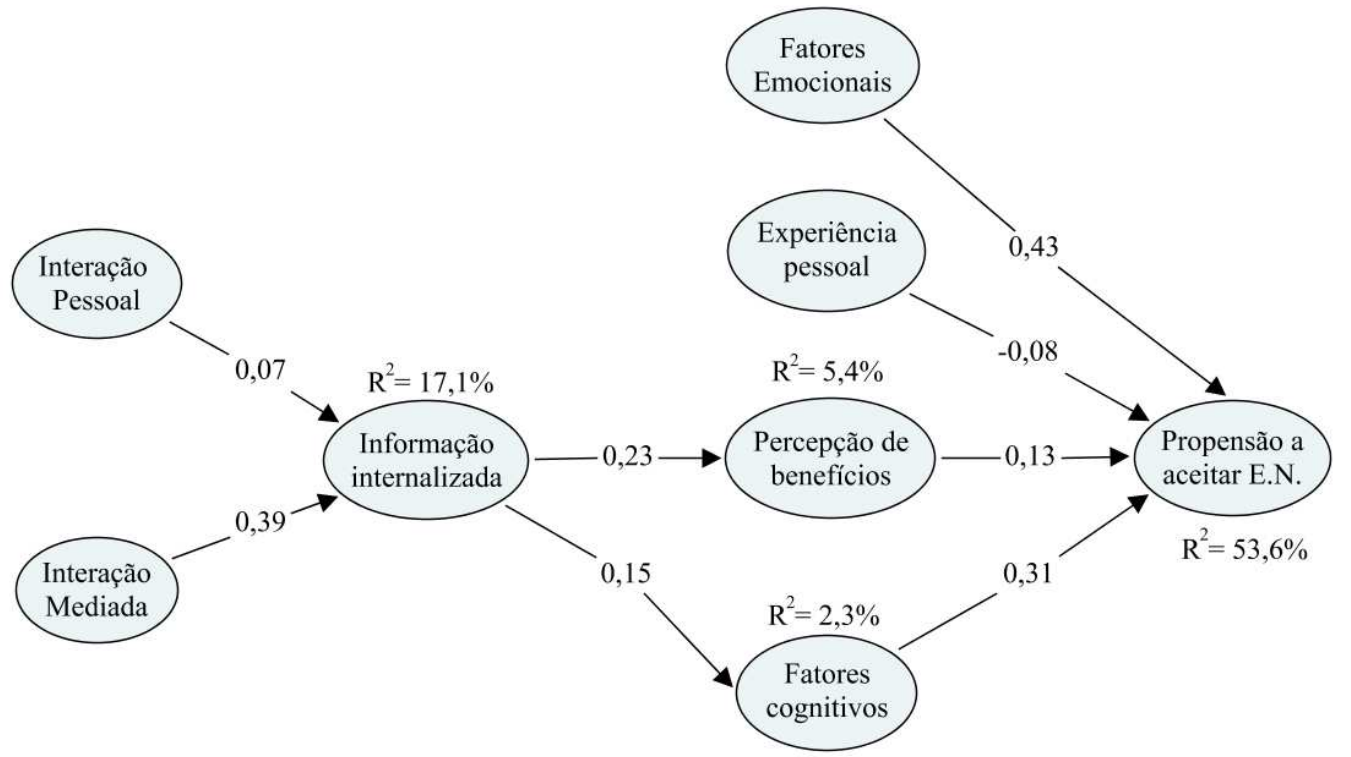

Fig 7 - Resultados para o modelo estrutural complementar

\subsection{Discussão dos resultados para os modelos estruturais}

As hipóteses apresentadas foram confirmadas, exceto as hipóteses $\mathrm{H} 1 \mathrm{a}(+)$ e $\mathrm{H} 3 \mathrm{a}(+)$ (ver fig. 8, a seguir). Estas apresentaram valores de coeficiente de regressão padronizados entre $-0,09$ e 0,10 , dependendo do modelo estrutural utilizado e do conjunto de dados utilizados.

Já a hipótese $\mathrm{H} 1 \mathrm{a}(+)$, que apresentou valores positivos e negativos e próximos de zero, indicando que não há qualquer correlação entre as experiências pessoais, conforme caracterizadas, e a propensão a aceitar a energia nuclear.

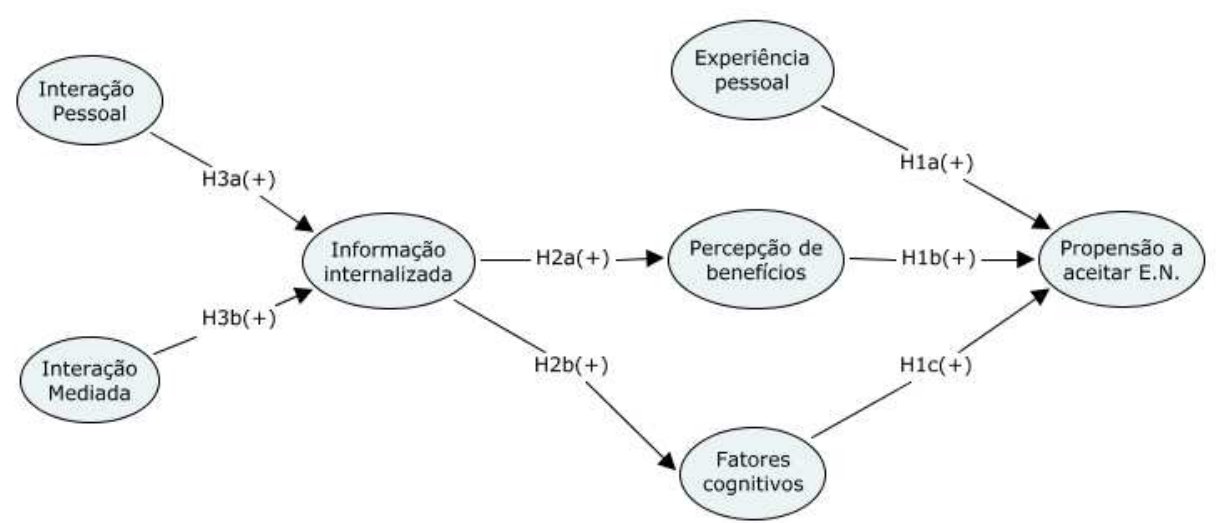

Fig. 8 - Hipóteses apresentadas

Para a hipótese $\mathrm{H} 3 \mathrm{a}(+)$, entende-se que os resultados indicam que as interações pessoais não influenciam suficientemente as informações internalizadas sobre energia para 
serem levadas em conta. Embora a variável latente para as informações internalizadas seja representadas apenas pelos meios onde os veículos de comunicação tomam parte (conforme mencionado no capítulo anterior), essa variável indica, de uma maneira global, aqueles que estão se informando sobre o assunto.

É razoável supor que espera-se que aqueles que conversem sobre o assunto "energia" devam também informar-se sobre esse assunto por meio dos veículos de comunicação. Porém, apesar destas considerações, os valores obtidos neste estudo apontam que as interações pessoais não afetam significativamente as informações internalizadas sobre energia.

Note que a variável latente para informações internalizadas quando era caracterizada inicialmente por informações sobre os veículos de comunicação e também por conversas em energia (Kiipper et al., 2011) ainda indicava uma não-correlação para a mesma hipótese $\mathrm{H} 3 \mathrm{a}(+)$, de 0,104.

A análise exploratória realizada no modelo original havia sugerido o agrupamento das interações pessoais entre interações político-profissionais e família-lazer. Para ambos os conjuntos de dados, não houve diferença significativa entre os valores de AVE, indicando que o resultado da hipótese $\mathrm{H} 3 \mathrm{a}(+)$ não pode ser justificado em nenhum desses grupos.

A hipótese $\mathrm{H} 3 \mathrm{a}(+)$ apresentou resultados baixos, pois, em ambos os conjuntos de dados, o número de respondentes que acusou conhecer alguém que trabalha em instalações nucleares e/ou alguém que tenha se submetido a tratamento com radiação, é muito baixo (cerca de $20 \%$, em ambos os casos).

As hipóteses $\mathrm{H} 2 \mathrm{a}(+)$ e $\mathrm{H} 2 \mathrm{~b}(+)$ apresentaram valores significativos, especialmente considerando que estas são caracterizadas pelo contato que o indivíduo tem com informações sobre energia nuclear no momento da pesquisa. Note que, caso estivéssemos diante de indivíduos que tiveram contato com o tema já a algum tempo, teríamos indivíduos que possuem informações internalizadas, mas não seriam caracterizados como tal. Há também as informações internalizadas por meio da educação em escolas e/ou faculdades, que também não são computadas no estudo.

Para os dados novos, a questão 11 apresentou um valor negativo (cerca de -0,7 nos dois modelos onde esse conjunto de dados é utilizado). Observamos que essa questão busca mensurar o quão importante os indivíduos consideram levar eletricidade para outros lares. As respostas para esse caso apresentaram variabilidade baixíssima (92\% dos respondentes marcaram "5 - muito importante"). Dado que a maioria dos respondentes 
também é contra as instalações nucleares, é de se esperar portanto esse coeficiente. Desse modo, essa questão foi desconsiderada.

Observando as variáveis latentes mais correlacionadas com a propensão a aceitar a energia nuclear, nos modelos pré e pós-Fukushima, notamos que para os dados antes do acidente, a percepção de benefícios era a variável latente mais correlacionada com esta propensão, com um fator de 0,49 enquanto que para os dados após o acidente, passou a ser a os fatores cognitivos, com correlação de 0,47 .

De acordo com diversos estudos (Williamson \& Weyman, 2005b), há uma assimetria entre os benefícios e os riscos percebidos. Num momento em que os riscos se tornam mais evidentes, há a tendência de se rejeitar e ignorar os benefícios. Já quanto ao aumento da correlação com os fatores cognitivos, podemos argumentar que a presença de alunos que visitaram a usina de Angra dos Reis pode ter elevado a correlação desta variável aos valores observados. Sabe-se que no momento da visita, esses conceitos (fatores cognitivos) são transmitidos, enquanto que os benefícios, conforme caracterizados por essa pesquisa não são. 


\section{Capítulo 6}

\section{CONCLUSÕES E RECOMENDAÇÕES}

A confiabilidade do modelo original proposto, além de ter sido colocada à prova nos testes estatísticos, mostrou solidez também na reprodutibilidade aplicada. Essa é uma característica fundamental para respaldar as conclusões abaixo.

As variáveis "interação pessoal" e "experiência pessoal” apresentaram baixa significância no entendimento da aceitação pública, pois no contexto das interações pessoais o tema da energia nuclear é pouco presente e as experiências pessoais sobre o assunto são extremamente escassas.

\subsection{Percepção pública antes e depois de Fukushima}

Tradicionalmente, o público brasileiro é contra as instalações nucleares, e após o acidente essa opinião tende a manter-se assim. Como uma opinião baseada em fatores cognitivos é mais sólida e normalmente reconhece e aceita a possibilidade de acidentes (além de avaliar mais racionalmente seus efeitos), nesses casos temos aqueles que sustem uma opinião favorável e que mantém essa posição.

Os dados apresentados sugerem que neste momento uma estratégia interessante para trabalhar a opinião pública é expandir os fatores cognitivos, certamente além daqueles apresentados neste trabalho. Caberia a esses interessados apresentar, por exemplo, outros dados relevantes tais como dimensões de um possível acidente. Observando a variável de primeira ordem "letalidade", onde muitos indivíduos, pró e contra energia nuclear, consideraram um acidente com um grande potencial de letalidade. Observa-se, até o momento desta pesquisa, nenhuma morte no acidente de Fukushima, devido aos efeitos da radiação e elementos radioativos liberada pelos reatores danificados (Terrell, 2011). 
Os resultados para AVE e CR para os modelos antes e depois de Fukushima estão apresentados nos APÊNDICES C e D, respectivamente. Os resultados são muito semelhantes, indicando uma consistência do modelo estrutural. As principais diferenças surgiram para as variáveis latentes interação político-profissional, e necessidade de eletricidade, cujos valores de AVE e CR apresentaram valores menores, e para a variável latente da comunicação audiovisual, cujos valores aumentaram do modelo pré para o modelo pós-Fukushima.

Embora o modelo original seja satisfatório, observamos que a variável latente "percepção de benefícios" é importante e pouco explicada pelas informações internalizadas. O mesmo ocorre, em menor escala, para os "fatores cognitivos". Isso ocorre pois o modelo estrutural em questão foi elaborado para buscar subsídios sobre onde agir na opinião pública.

\subsection{O modelo complementar}

Os fatores emocionais desempenham um papel fundamental na constituição da propensão a aceitar a energia nuclear, que no modelo original havia sido descartado, pois suas variáveis amostrais não haviam sido bem escolhidas. Comparando os valores de $\mathrm{R}^{2}$, observa-se um aumento de 40,5\% para 53,6\%. Isso significa que essa variável dependente é melhor explicada com a presença da variável latente em questão. Há a importância de se estudar as antecedentes das variáveis latentes para os fatores emocionais para se obter subsídios para a comunicação com o público.

A importância dos fatores emocionais evidencia-se na relação que estes têm com a propensão em aceitar a energia nuclear, observando-se na figura 7 uma correlação equivalente a 0,43 . Os valores para os fatores cognitivos e percepção de benefícios, sendo respectivamente 0,31 e 0,13 para o modelo complementar (pós-fukushima) e 0,25 e 0,49 para o modelo original (pré-fukushima) são entendidos a partir dos valores de $\mathrm{R}^{2}$ de cada uma dessas variáveis, que nesse caso ficou entre 2,3 e 6,3\% apenas. 
APÊNDICE A - Termo de consentimento livre e esclarecido

TERMO DE CONSENTIMENTO FORMAL
LIVRE E ESCLARECI
Consentimento formal de participação no estudo intitula
DE RISCO DAS INSTALAÇÕES NUCLEARES”
Pós-graduando Responsável: Felipe de Moura Kiipper
Orientador: Prof. Dr. Antonio Carlos de Oliveira Barroso
Colaboradores: Prof. Dr. Kengo Imakuma
Prof. Dr. Diógenes Souza Bido
Esclarecimento Geral

Este estudo tem como objetivo investigar a percepção pública em relação a instalações nucleares na Grande São Paulo. Esta investigação será realizada por meio de alguns critérios reconhecidos e outros que ainda não foram utilizados. Além disso, pretendemos com o presente projeto aprimorar o modelo de percepção pública desenvolvido pelo grupo de pesquisa, através de métodos estatísticos pertinentes.

\section{Explicação do Procedimento:}

Após seu consentimento, os procedimentos serão explicados e você será submetido a uma avaliação escrita. Esta avaliação é composta por 30 questões de múltipla escolha além de um breve cabeçalho onde são solicitados dados como nome, idade, e-mail, sexo e telefone celular. Deste modo, o pesquisador avaliará através de suas respostas a sua opinião em relação às instalações nucleares em diferentes aspectos, de acordo com as necessidades de pesquisa.

Declaramos que não existem benefícios diretos para o voluntário durante a participação nesta pesquisa e os resultados obtidos pelos pesquisadores responsáveis auxiliarão no maior conhecimento a respeito da maneira como indivíduos percebem as instalações nucleares, em especial quanto aos seus riscos e benefícios. Asseguramos que os procedimentos empregados neste estudo não provocarão qualquer tipo de risco ou desconforto para o voluntário, não existindo nenhum tipo de seguro do qual o voluntário possa se beneficiar.

Garantimos que quaisquer dúvidas que surjam antes, durante ou posteriormente aos procedimentos desta pesquisa serão devidamente esclarecidas.

Prof. Dr. Antônio Carlos de Oliveira Barroso

Instituto de Pesquisas Energéticas Nucleares - IPEN/USP

Contato: (11) 3133-9154 
$\mathrm{Eu}$, $\mathrm{RG}$ no: residente

à bairro , cidade: , no , declaro que tenho anos

de idade e que concordo participar, voluntariamente, na pesquisa conduzida pelos alunos responsáveis e por seu(sua) respectivo(a) orientador(a).

Declaro estar ciente de minha participação na pesquisa intitulada "ESTUDO DA PERCEPÇÃO PÚBLICA DE RISCO DAS INSTALAÇÕES NUCLEARES" e dou plena autorização e consentimento à Universidade de São Paulo (USP), através do Instituto de Pesquisas Energéticas e Nucleares, para realizar a apliação de questionário pertinente ao estudo.

Declaro ter conhecimento de que não existem benefícios diretos a minha pessoa durante a participação nesta pesquisa e de que não serei submetido a nenhum tipo de procedimento sem meu consentimento prévio e de que os mesmos não provocarão qualquer tipo de desconforto ou risco a minha saúde, não existindo nenhum tipo de seguro de saúde que eu possa me beneficiar.

A minha participação neste estudo é voluntária, sendo meu direito interromper minha participação, a qualquer momento, sem qualquer questionamento ou prejuízo à minha pessoa. Estou ciente também que o pesquisador tem o direito de excluir meus dados no caso de abandono do experimento, coleta incompleta ou conduta inadequada durante o período de coleta. As informações obtidas nesta pesquisa não serão associadas à minha identidade e não poderão ser consultadas por pessoas que não sejam da área, sem minha autorização oficial. Estas informações poderão ser utilizadas para fins estatísticos ou científicos, desde que fiquem resguardados a minha total privacidade e o meu anonimato.

Os responsáveis pelo estudo me explicaram todos os riscos envolvidos, a necessidade da pesquisa e se prontificaram a responder todas as minhas questões sobre o experimento, sendo meu direito manter uma cópia deste consentimento.

São Paulo - SP, de de 2011

Assinatura do Voluntário ou Responsável:

\section{Felipe de Moura Kiipper (Pesquisador Responsável)}

Pós-Graduando em Tecnologia nuclear - Reatores Instituto de Pesquisas Energéticas e Nucleares - IPEN - CNEN/USP

Gestão do conhecimento aplicada a área nuclear

DÚVIDAS: (11) 3133-9154 
APENDICE B - Modelo do questionário aplicado

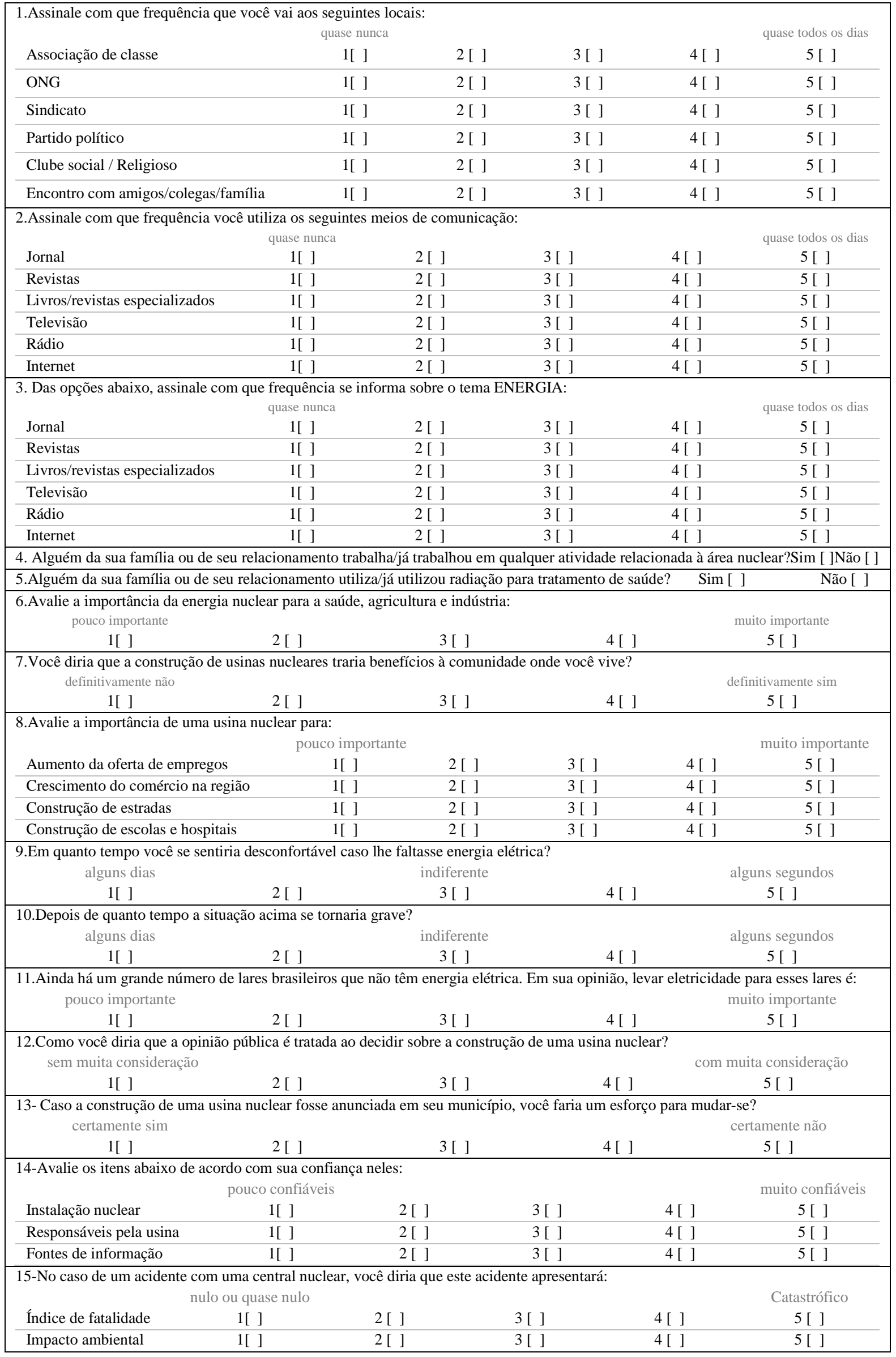




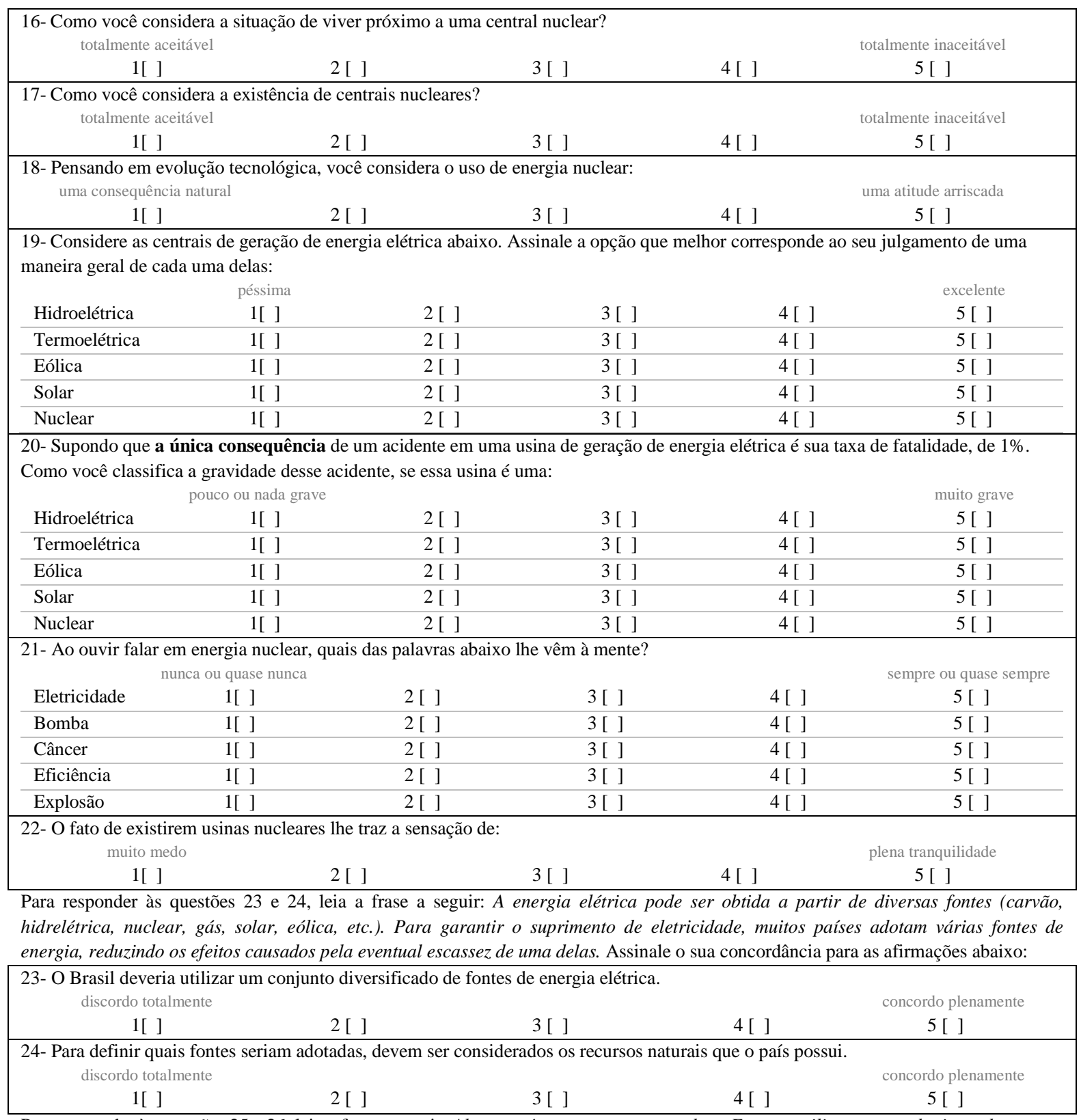

Para responder às questões 25 e 26, leia a frase a seguir: Alguns países como, por exemplo, a França, utilizam a tecnologia nuclear como principal fonte de geração de energia. Assinale o seu grau de concordância em relação às afirmações abaixo:

25- Eles estão corretos porque é uma boa solução para atender às necessidades de energia elétrica. discordo totalmente

$1[$ ]

2 [ ]

3 [ ]

4 [ ]

concordo plenamente

5 [ ]

26- Eles estão corretos devido às características dos recursos naturais disponíveis em seu território. discordo totalmente
$1[$ ]
2 [ ]
3 [ ]
4 [ ]

concordo plenamente

5 [ ]

27-Se fosse consultado a respeito da construção de mais usinas nucleares no Brasil para geração de eletricidade, qual seria a sua opinião? discordo totalmente

$3[$ ]

4 [ ]

concordo plenamente

28.Atualmente 3\% da energia elétrica gerada no Brasil é obtida através de tecnologia nuclear. Em sua opinião, qual deveria ser a participação da energia nuclear na matriz elétrica do país dentro de 30 anos?
menos que $1 \%$ entre $1-5 \%$
entre $5-10 \%$ entre $10-30 \%$
[ ]
mais que $30 \%$
não tenho opinião
[ ]
[ ]
[ ]
[ ]
[ ]

Para responder às questões 29 e 30 , assinale o quanto você concorda com as afirmações:

29. "Centrais nucleares para geração de energia elétrica são aceitáveis mesmo em um raio de 30 km da minha residência". discordo totalmente
$1[$ ]
2 [ ]
3 [ ]
4 [ ]

concordo plenamente

30. "Centrais nucleares para geração de energia elétrica são aceitáveis quando distantes de centro urbanos". discordo totalmente

1[]

2 [ ]

3 [ ]

4 [ ]

concordo plenamente

5 [ ] 
APÊNDICE C - Modelo estrutural completo

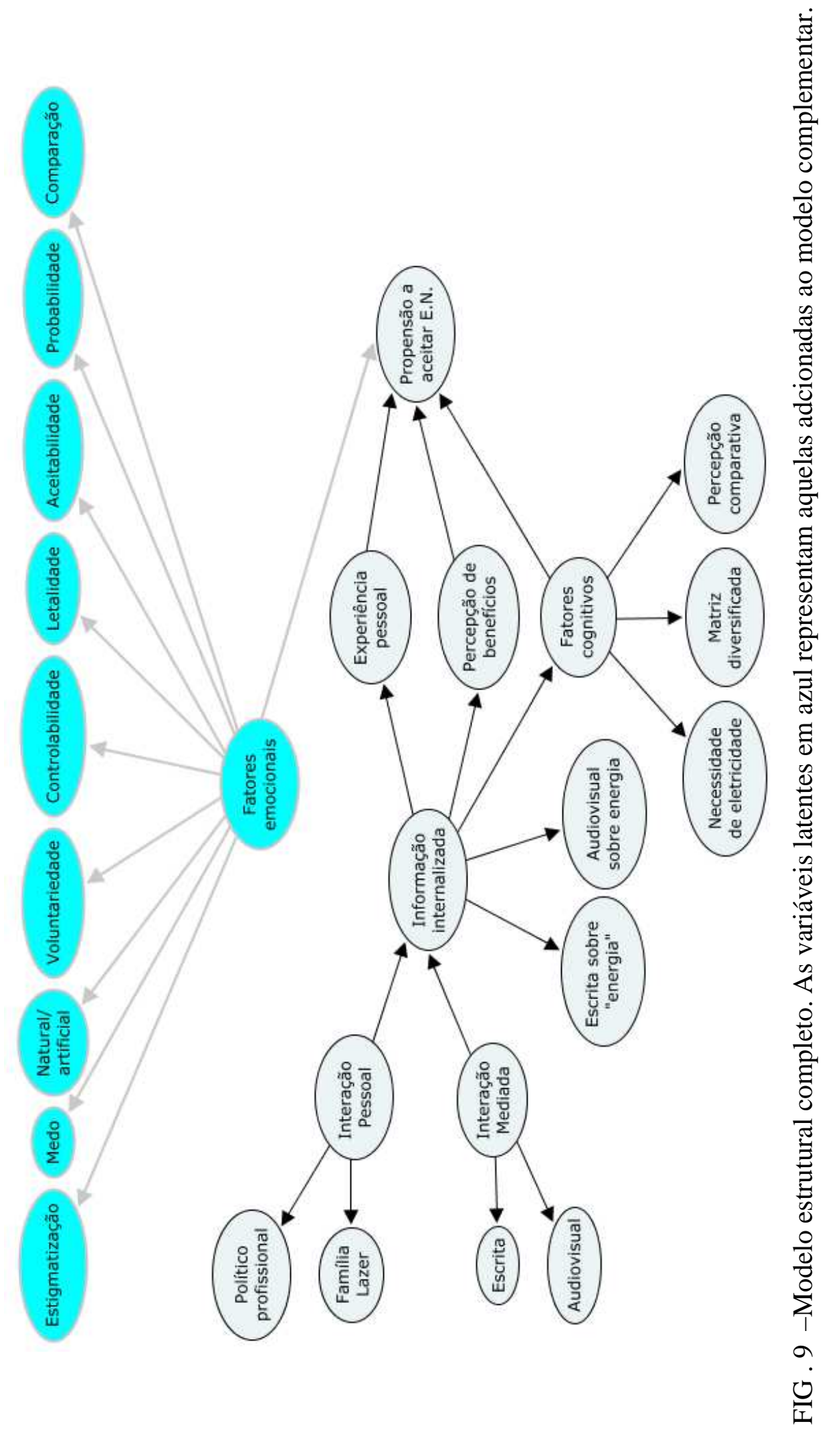


APÊNDICE D - Indicadores para VL de $1^{\text {a }}$ ordem - Modelo original, Pré-Fukushima

\begin{tabular}{|c|c|c|c|c|}
\hline $\begin{array}{c}\text { Variável } \\
\text { latente }\end{array}$ & Indicadores & $\begin{array}{c}\text { Carga } \\
\text { fatorial }\end{array}$ & $\mathbf{A V E}^{1}$ & $\mathbf{C} \mathbf{R}^{2}$ \\
\hline \multirow{4}{*}{$\begin{array}{c}\text { Político } \\
\text { profissional }\end{array}$} & Frequência que visita a associações de cla & 0,61 & \multirow{4}{*}{0,68} & \multirow{4}{*}{0,89} \\
\hline & Frequência que visita ONGs. & 0,81 & & \\
\hline & Frequência que visita um sindicato. & 0,89 & & \\
\hline & Frequência que visita partidos políticos. & 0,94 & & \\
\hline \multirow{2}{*}{ Família-lazer } & Frequência que vai a clube social/religios & 0,81 & \multirow{2}{*}{0,60} & \multirow{2}{*}{0,75} \\
\hline & Frequência que se fala com amigos/colegas/família. & 0,73 & & \\
\hline \multirow{3}{*}{$\begin{array}{c}\text { Interação } \\
\text { escrita }\end{array}$} & Frequência que lê jornais. & 0,59 & \multirow{3}{*}{0,57} & \multirow{3}{*}{0,80} \\
\hline & Frequência que lê revistas. & 0,85 & & \\
\hline & Frequência que lê livros/revistas especializados. & 0,81 & & \\
\hline \multirow{3}{*}{$\begin{array}{c}\text { Interação } \\
\text { audiovisual }\end{array}$} & Frequência que assiste à televisão. & 0,70 & \multirow{3}{*}{0,49} & \multirow{3}{*}{0,74} \\
\hline & Frequência que escuta o rádio. & 0,75 & & \\
\hline & Frequência que acessa a internet. & 0,65 & & \\
\hline \multirow{3}{*}{ Escrita } & Frequência que lê sobre "energia" em jornais. & 0,67 & \multirow{3}{*}{0,61} & \multirow{3}{*}{0,82} \\
\hline & Frequência que lê sobre "energia" em revistas. & 0,87 & & \\
\hline & Freq. que lê sobre "energia" em livros/revistas espec. & 0,79 & & \\
\hline \multirow{3}{*}{ Audiovisual } & Frequência que vê o tema "energia" na televisão. & 0,80 & \multirow{3}{*}{0,59} & \multirow{3}{*}{0,81} \\
\hline & Frequência que escuta sobre "energia" no rádio. & 0,77 & & \\
\hline & Frequência que vê o tema "energia" na internet. & 0,72 & & \\
\hline \multirow{2}{*}{$\begin{array}{l}\text { Experiência } \\
\text { anterior }\end{array}$} & Familiar/conhecido já trabalhou com energia nuclear & 0,50 & \multirow{2}{*}{0,55} & \multirow{2}{*}{0,70} \\
\hline & Familiar/conhecido já usou radiação para saúde. & 0,71 & & \\
\hline \multirow{6}{*}{$\begin{array}{l}\text { Percepção de } \\
\text { benefícios }\end{array}$} & Importância da E.N. na saúde, agricultura e ind & 0,50 & \multirow{6}{*}{0,50} & \multirow{6}{*}{0,86} \\
\hline & Se a E.N. traz benefícios a comunidade onde vive. & 0,71 & & \\
\hline & Importância para crescimento de empregos. & 0,77 & & \\
\hline & Importância para crescimento do comércio local. & 0,80 & & \\
\hline & Importância para construção de estradas. & 0,74 & & \\
\hline & Importância para construção de escolas e hospitais. & 0,69 & & \\
\hline \multirow{3}{*}{$\begin{array}{c}\text { Necessidade } \\
\text { de } \\
\text { eletricidade }\end{array}$} & Tempo para desconforto caso ficasse sem eletricidade. & 0,76 & \multirow{3}{*}{0,53} & \multirow{3}{*}{0,77} \\
\hline & Após quanto tempo a situação se torna grave. & 0,70 & & \\
\hline & Importância de levar eletricidade a lares que não têm. & 0,73 & & \\
\hline \multirow{2}{*}{$\begin{array}{c}\text { Matriz } \\
\text { diversificada }\end{array}$} & Brasil deve usar um conjunto de fontes diversificadas. & 0,83 & & \\
\hline & Recursos naturais devem influencias escolhas. & 0,82 & 0,68 & 0,81 \\
\hline Percepção & França deve usar E.N. para suas necessidades. & 0,89 & & 0,87 \\
\hline & França deve usar E.N. de acordo com seus recursos. & 0,87 & & $0,8 /$ \\
\hline & Concorda em construir usinas nucleares no Brasil? & 0,83 & & \\
\hline Propensão a & Participação da E.N. no Brasil em 30 anos. & 0,74 & & \\
\hline & A favor mesmo que a $30 \mathrm{~km}$ da minha residência. & 0,60 & & \\
\hline & A favor desde que distante de centros urbanos. & 0,57 & & \\
\hline
\end{tabular}

\footnotetext{
${ }^{\mathrm{I}}$ Average variance extracted
}

${ }^{2}$ Composite reliability 
APÊNDICE E - Indicadores para VL de $1^{\mathrm{a}}$ ordem - Modelo original, Pós-Fukushima

\begin{tabular}{|c|c|c|c|c|}
\hline $\begin{array}{l}\text { Variável } \\
\text { latente }\end{array}$ & Indicadores & $\begin{array}{c}\text { Carga } \\
\text { fatorial }\end{array}$ & $\mathbf{A V E}^{1}$ & $\mathbf{C} \mathbf{R}^{2}$ \\
\hline \multirow{4}{*}{$\begin{array}{c}\text { Político } \\
\text { profissional }\end{array}$} & Frequência que visita a associações de cl & 0,58 & \multirow{4}{*}{0,51} & \multirow{4}{*}{0,81} \\
\hline & Frequência que visita ONGs. & 0,73 & & \\
\hline & Frequência que visita um sindicato. & 0,80 & & \\
\hline & Frequência que visita partidos políticos. & 0,73 & & \\
\hline \multirow{2}{*}{ Família-lazer } & Frequência que vai a clube social/religio & 0,98 & \multirow{2}{*}{0,56} & \multirow{2}{*}{0,68} \\
\hline & Frequência que se fala com amigos/colegas/família. & 0,40 & & \\
\hline \multirow{3}{*}{$\begin{array}{c}\text { Interação } \\
\text { escrita }\end{array}$} & Frequência que lê jornais. & 0,76 & \multirow{3}{*}{0,62} & \multirow{3}{*}{0,83} \\
\hline & Frequência que lê revistas. & 0,86 & & \\
\hline & Frequência que lê livros/revistas especializados. & 0,75 & & \\
\hline \multirow{3}{*}{$\begin{array}{l}\text { Interação } \\
\text { audiovisual }\end{array}$} & Frequência que assiste à televisão. & 0,75 & \multirow{3}{*}{0,45} & \multirow{3}{*}{0,69} \\
\hline & Frequência que escuta o rádio. & 0,81 & & \\
\hline & Frequência que acessa a internet. & 0,35 & & \\
\hline \multirow{3}{*}{ Escrita } & Frequência que lê sobre "energia" e & 0,83 & \multirow{3}{*}{0,63} & \multirow{3}{*}{0,84} \\
\hline & Frequência que lê sobre "energia" em revistas. & 0,85 & & \\
\hline & Freq. que lê sobre "energia" em livros/revistas espec. & 0,69 & & \\
\hline \multirow{3}{*}{ Audiovisual } & Frequência que vê o tema "energia" na televisão. & 0,88 & \multirow{3}{*}{0,68} & \multirow{3}{*}{0,86} \\
\hline & Frequência que escuta sobre "energia" no rádio. & 0,76 & & \\
\hline & Frequência que vê o tema "energia" na internet. & 0,83 & & \\
\hline \multirow{2}{*}{$\begin{array}{l}\text { Experiência } \\
\text { anterior }\end{array}$} & Familiar/conhecido já trabalhou com energia nuclear. & 0,67 & \multirow{2}{*}{0,56} & \multirow{2}{*}{0,72} \\
\hline & Familiar/conhecido já usou radiação para saúde. & 0,82 & & \\
\hline \multirow{6}{*}{$\begin{array}{l}\text { Percepção de } \\
\text { benefícios }\end{array}$} & Importância da E.N. na saúde, agricultura e ind & 0,66 & \multirow{6}{*}{0,53} & \multirow{6}{*}{0,87} \\
\hline & Se a E.N. traz benefícios a comunidade onde vive. & 0,78 & & \\
\hline & Importância para crescimento de empregos. & 0,71 & & \\
\hline & Importância para crescimento do comércio local. & 0,80 & & \\
\hline & Importância para construção de estradas. & 0,71 & & \\
\hline & Importância para construção de escolas e hospitais. & 0,68 & & \\
\hline \multirow{3}{*}{$\begin{array}{c}\text { Necessidade } \\
\text { de } \\
\text { eletricidade }\end{array}$} & Tempo para desconforto caso ficasse sem eletricidade. & 0,65 & \multirow{3}{*}{0,37} & \multirow{3}{*}{0,06} \\
\hline & Após quanto tempo a situação se torna grave. & 0,41 & & \\
\hline & Importância de levar eletricidade a lares que não têm. & $-0,72$ & & \\
\hline \multirow{2}{*}{$\begin{array}{c}\text { Matriz } \\
\text { diversificada }\end{array}$} & Brasil deve usar um conjunto de fontes diversificadas. & 0,86 & 069 & 082 \\
\hline & & 0,80 & 0,69 & \\
\hline Percepção & França deve usar E.N. para suas necessidades. & 0,88 & & \\
\hline & França deve usar E.N. de acordo com seus recu & 0,87 & & \\
\hline & Concorda em construir usinas nucleares no Brasil? & 0,86 & & \\
\hline Propensão a & Participação da E.N. no Brasil em 30 anos. & 0,70 & & \\
\hline & A favor mesmo que a $30 \mathrm{~km}$ da minha residência. & 0,59 & & \\
\hline & A favor desde que distante de centros urbanos. & 0,48 & & \\
\hline
\end{tabular}

${ }^{\mathrm{I}}$ Average variance extracted

${ }^{2}$ Composite reliability 
APÊNDICE F - Indicadores para VL de $1^{\text {a }}$ ordem - Modelo complementar

\begin{tabular}{|c|c|c|c|c|}
\hline $\begin{array}{l}\text { Variável } \\
\text { latente }\end{array}$ & Indicadores & $\begin{array}{c}\text { Carga } \\
\text { fatorial }\end{array}$ & $\mathbf{A V E}^{\mathbf{1}}$ & $\mathbf{C R}^{2}$ \\
\hline \multirow{4}{*}{$\begin{array}{c}\text { Político } \\
\text { profissional }\end{array}$} & Frequência que visita a associações de cl & 0,59 & \multirow{4}{*}{0,51} & \multirow{4}{*}{0,81} \\
\hline & Frequência que visita ONGs. & 0,72 & & \\
\hline & Frequência que visita um sindicato. & 0,80 & & \\
\hline & Frequência que visita partidos políticos. & 0,73 & & \\
\hline \multirow{2}{*}{ Família-lazer } & Frequência que vai a clube social/religios & 0,97 & \multirow{2}{*}{0,56} & \multirow{2}{*}{0,68} \\
\hline & Frequência que se fala com amigos/colegas/família. & 0,40 & & \\
\hline \multirow{3}{*}{$\begin{array}{c}\text { Interação } \\
\text { escrita }\end{array}$} & Frequência que lê jornais. & 0,76 & \multirow{3}{*}{0,62} & \multirow{3}{*}{0,83} \\
\hline & Frequência que lê revistas. & 0,86 & & \\
\hline & Frequência que lê livros/revistas especializados. & 0,75 & & \\
\hline \multirow{3}{*}{$\begin{array}{c}\text { Interação } \\
\text { audiovisual }\end{array}$} & Frequência que assiste à televisão. & 0,75 & \multirow{3}{*}{0,45} & \multirow{3}{*}{0,69} \\
\hline & Frequência que escuta o rádio. & 0,81 & & \\
\hline & Frequência que acessa a internet. & 0,35 & & \\
\hline \multirow{3}{*}{ Escrita } & Frequência que lê sobre "energia" en & 0,83 & \multirow{3}{*}{0,63} & \multirow{3}{*}{0,84} \\
\hline & Frequência que lê sobre "energia" em revistas. & 0,85 & & \\
\hline & Freq. que lê sobre "energia" em livros/revistas espec. & 0,69 & & \\
\hline \multirow{3}{*}{ Audiovisual } & Frequência que vê o tema "energia" na televisão. & 0,88 & \multirow{3}{*}{0,68} & \multirow{3}{*}{0,86} \\
\hline & Frequência que escuta sobre "energia" no rádio. & 0,76 & & \\
\hline & Frequência que vê o tema "energia" na internet. & 0,83 & & \\
\hline \multirow{2}{*}{$\begin{array}{l}\text { Experiência } \\
\text { anterior }\end{array}$} & Familiar/conhecido já trabalhou com energia nuclear. & $-0,12$ & \multirow{2}{*}{0,48} & \multirow{2}{*}{0,41} \\
\hline & Familiar/conhecido já usou radiação para saúde. & 0,97 & & \\
\hline \multirow{6}{*}{$\begin{array}{l}\text { Percepção de } \\
\text { benefícios }\end{array}$} & Importância da E.N. na saúde, agricultura e indústria. & 0,65 & \multirow{6}{*}{0,53} & \multirow{6}{*}{0,87} \\
\hline & Se a E.N. traz benefícios a comunidade onde vive. & 0,79 & & \\
\hline & Importância para crescimento de empregos. & 0,70 & & \\
\hline & Importância para crescimento do comércio local. & 0,80 & & \\
\hline & Importância para construção de estradas. & 0,71 & & \\
\hline & Importância para construção de escolas e hospitais. & 0,69 & & \\
\hline \multirow{3}{*}{$\begin{array}{c}\text { Necessidade } \\
\text { de } \\
\text { eletricidade }\end{array}$} & Tempo para desconforto caso ficasse sem eletricidade. & 0,94 & \multirow{3}{*}{0,37} & \multirow{3}{*}{0,05} \\
\hline & Após quanto tempo a situação se torna grave. & 0,55 & & \\
\hline & Importância de levar eletricidade a lares que não têm. & $-0,73$ & & \\
\hline \multirow{2}{*}{$\begin{array}{c}\text { Matriz } \\
\text { diversificada }\end{array}$} & Brasil deve usar um conjunto de fontes diversificadas. & 0,86 & 069 & \\
\hline & Recursos naturais devem influencias escolhas. & 0,80 & 0,69 & 0,8 \\
\hline Percepção & França deve usar E.N. para suas necessidades. & 0,88 & & \\
\hline & França deve usar E.N. de acordo com seus recu & 0,87 & & \\
\hline & Concorda em construir usinas nucleares no Brasil? & 0,87 & & \\
\hline Propensão a & Participação da E.N. no Brasil em 30 anos. & 0,71 & & \\
\hline & A favor mesmo que a $30 \mathrm{~km}$ da minha residência. & 0,62 & & \\
\hline & A favor desde que distante de centros urbanos. & 0,40 & & \\
\hline
\end{tabular}

\footnotetext{
${ }^{\mathrm{T}}$ Average variance extracted
}

${ }^{2}$ Composite reliability 
APÊNDICE G - Indicadores para VL de $1^{\text {a }}$ ordem - Modelo complementar (f. emocionais)

\begin{tabular}{|c|c|c|c|c|}
\hline $\begin{array}{l}\text { Variável } \\
\text { latente }\end{array}$ & Indicadores & $\begin{array}{c}\text { Carga } \\
\text { fatorial }\end{array}$ & $\mathrm{AVE}^{1}$ & $\mathbf{C R}^{2}$ \\
\hline \multirow{5}{*}{ Estigma } & Ao ouvir falar de E.N. lembra de "Eletricidade" & 0,53 & \multirow{5}{*}{0,33} & \multirow{5}{*}{0,70} \\
\hline & Ao ouvir falar de E.N. lembra de "Bomba" & 0,63 & & \\
\hline & Ao ouvir falar de E.N. lembra de "Câncer" & 0,51 & & \\
\hline & Ao ouvir falar de E.N. lembra de "Eficiência" & 0,48 & & \\
\hline & Ao ouvir falar de E.N. lembra de "Explosão" & 0,69 & & \\
\hline Medo & Usinas nucleares lhe trazem a sensação de medo & 1,00 & 1,00 & 1,00 \\
\hline Natural/artificial & Para avanço tecnológico, E.N. é natural/artificial? & 1,00 & 1,00 & 1,00 \\
\hline \multirow{2}{*}{ Voluntariedade } & Como a opinião pública é tratada para E.N.? & 0,53 & \multirow{2}{*}{0,53} & \multirow{2}{*}{0,68} \\
\hline & Mudaria-se se construissem uma usina nuclear? & 0,90 & & \\
\hline \multirow{3}{*}{ Controlabilidade } & Confiança na instalação nuclear. & 0,87 & \multirow{3}{*}{0,73} & \multirow{3}{*}{0,89} \\
\hline & Confiança com os responsáveis pela usina. & 0,92 & & \\
\hline & Confiança com as fontes de informação. & 0,77 & & \\
\hline \multirow{2}{*}{ Letalidade } & Fatalidade, para o caso de um acidente. & 0,94 & \multirow{2}{*}{0,85} & \multirow{2}{*}{0,92} \\
\hline & Impacto ambiental, para o caso de um acidente. & 0,90 & & \\
\hline \multirow{2}{*}{ Aceitabilidade } & Como considera viver próximo a usina nuclear. & 0,89 & \multirow{2}{*}{0,79} & \multirow{2}{*}{0,88} \\
\hline & Como considera a existência de usinas nucleares. & 0,88 & & \\
\hline Probabilidade & Relação das emoções para E.N. com outras fontes. & 1,00 & 1,00 & 1,00 \\
\hline Comparação & Julgamento entre diversas fontes de E.N. & 1,00 & 1,00 & 1,00 \\
\hline
\end{tabular}




\section{REFERÊNCIAS BIBLIOGRÁFICAS}

BARKE, R. P.; JENKINS-SMITH, H.; SLOVIC, P. Risk perceptions of men and women scientists. Austin, TX, 1997. Social Science Quarterly, v. 78. n. 1. Disponível em: <http://doi.apa.org/?uid=1997-03447-005> Acesso em 08 fev. 2011

BARROSO, A. C. de O. TNA 5776 - Tópicos especiais em gestão do conhecimento, Instituto de pesquisas Energéticas e Nucleares. São Paulo. 2010

BERNSTEIN, P. L. Against the gods New York, N.Y.: Wiley. 1996

BISCONTI RESEARCH. Fourth Biennial Nuclear Power Plant Neighbor Public Opinion Tracking Survey, jun. 2011a Disponível em:

<http://www.nei.org/filefolder/Plant_Neighbor_topline_memo_2011.pdf> Acesso em 13 nov. 2011.

BISCONTI RESEARCH. Latest Trends in U. S. Public Opinion about Nuclear Energy, set. 2011b Disponível em:

<http://www.nei.org/filefolder/2011_Sept_Public_Opinion_Tracking_Memo_Post.pdf> Acesso em 16 nov 2011.

BREAKWELL, G. M., BARNETT, J., LOFSTEDT, R., KEMP, R., \& GLASER, C. The Impact of Social Amplification of Risk on Risk Communication. Health and Safety Executive, Guildford, 2011 Disponível em:

<http://www.hse.gov.uk/research/crr_pdf/2001/crr01332.pdf> Acesso em 2 jan. 2012.

CHIN, W. W.; NEWSTED, P.R. Structural Equation Modeling Analysis With Small Sample Using Partial Least Squares. In:

HOYLE, R. H. Statistical Strategies For Small Sample Research, Sage, 1999 p.307-339

CROUCH, E. A. C., \& WILSON, R. Risk/benefit analysis. Cambridge, 1982. Ballinger Publishing Company. Disponível em:

<http://www.osti.gov/energycitations/product.biblio.jsp?osti_id=5557457> Acesso em 17 set. 2011.

DAMASIO, A. Descartes’ Error 1994, Avon.

EUROBAROMETER. Attitudes towards radioactive waste. Nuclear Energy: jun. 2008.

KIIPPER, F. M.; BARROSO, A. C. O.; BIDO, D.S. Public Perception of Risk on Nuclear Installations. Z. Guzović, In: 6th DUBROVNIK CONFERENCE ON SUSTAINABLE DEVELOPMENT OF ENERGY, WATER AND ENVIRONMENT SYSTEMS sep 2430, 2011, Dubrovnik, Croatia. Proceedings... p. 180-181

FORNELL, C.; LARCKER, D. F.; Evaluating structural equation models with unobservable variables and measurent models. Journal of Marketing Research, fev. 1981. v. 18 p.39-50. 
FREWER, L. J. Environmental risk, public trust and perceived exclusion from risk management. Research in Social Problems and Public Policy, 2001. v.9 p.221-248. Emerald Group Publishing Limited.

HENSELER, J.; RINGLE, C. M.; SINKOVICS, R. R.; The use of partial least squares path modeling in international marketing. Advances in international marketing, v.20, p.277-319, 2009

HOEL, P. G. Estatística Elementar. ed.1. São Paulo : Atlas, 1981.

INHABER, H. Energy risk assessment. 1982, Routledge.

KEMP, R. V.; CRAWFORD, M. B.; TWIGGER-ROSS, S. J. T.; FISCHER, J.; WEATHERLY, N. Strategic Risk Assessment: Phase II. Environmental Agency R\&D, 2002 (Project E2-041).

NAIDOO, D. Accepance is key for a Nuclear Renaissance. Sidmouth, UK: Nuclear Future, 2006, v. 2 n. 6, p. 264-271.

PIDGEON, N. Risk assessment, risk values and the social science programme: why we do need risk perception research. Bangor, UK: Reliability Engineering \& System Safety, 1998 , v. 59 n. 1, p. 5-15.

PIDGEON, N.; HOOD, C.; JONES, D. Risk: analysis, perception and management. analysis, perception. 1992, Royal society

RENN, O. Social amplification of risk in participation: two case studies. In. The social amplification of risk. Cambridge, 2003, Cambridge University.

RIBEIRO JÚNIOR, J.A. Um Estudo Simplificado da Percepção Pública dos Benefícios e Riscos de Centrais Termonucleares. 2007. Dissertação (Mestrado) - Instituto de Pesquisas Energéticas e Nucleares, São Paulo.

SAUER, M. E. L. J.; NETO, J. M. O. Comunicação de risco na área nuclear. In: VII CONGRESSO GERAL DE ENERGIA NUCLEAR, 27-30 out.1999. Belo Horizonte: ABEN.

SJÖBERG, L. Perceived risk and tampering with nature. 2000, Stockholm: Journal of Risk Research, v. 3 n. 4, p. 353-367.

SJÖBERG, L. The diferent dynamics of personal and general risk. Stockholm: Risk Management: An international Journal, 2003, v.5 n.3, p. 19-34.

SJÖBERG, L. Rational Risk Perception: Utopia or Dystopia? 2006, Stockholm:Journal of Risk Research, v. 9 n.6, p. 683-696.

SLOVIC, P. Trust, emotion, sex, politics, and science: surveying the risk-assessment battlefield. 1999, Eugene, OR:Risk analysis, v.19 n.4, p. 689-701. Disponível em: <http://www.ncbi.nlm.nih.gov/pubmed/10765431> Acesso em 9 jan. 2012. 
SLOVIC, PAUL. Perception of risk. 1987, Washington, DC:Science, v. 236 n.4799, p. 280-285. Disponível em: 〈http://www.sciencemag.org/content/236/4799/280.short> Acesso em 3 jun. 2011

SLOVIC, P.; FINUCANE, M. L.; PETERS, E.; \& MACGREGOR, D. G.; Risk as analysis and risk as feelings: some thoughts about affect, reason, risk, and rationality. 2004, Eugene, OR:Risk analysis, v. 24 n.2, p. 311-322.

STARR, C. Social benefit versus technological risk. 1969, Washington, DC:Science, v. 165 , p.1232-1238.

TERRELL, R. No Fukushima Radiation Deaths - No Surprises. 2011, The New American. Disponível em: <http://thenewamerican.com/tech-mainmenu30/environment/9537-no-fukushima-radiation-deaths-no-surprises> Acesso em 11 jan. 2012.

U.S. DEPARTMENT OF ENERGY The History of Nuclear Energy Development. Washington, DC ,1994. Disponível em: <http://www.ne.doe.gov/pdfFiles/History.pdf> Acesso em 23 jan. 2011.

WALKER, G.; SIMMONS, P.; WYNNE, B.; IRWIN, A. Public perception of risks associated with major accident hazards. 1998. Bootle:HSE Contract Research Report.

WEYMAN, A.; KELLY, C. J. Risk perception and risk communication: A review of the literature and communication. Sheffield:HSE, 1999.

WILlIAMSON, J.; WEYMAN, A. Review of the Public Perception of Risk, and Stakeholder Engagement. Buxton:HSL, 2005.

WÅHLBERG, A. The theoretical features of some current approaches to risk perception. 2001, London:Journal of risk research, v. 4 n.3, p.237-250. Disponível em: <http://www.tandfonline.com/doi/abs/10.1080/13669870152023791> Acesso em 13 mar. 2011. 